\title{
A cyclin-dependent kinase, CDK11/p58, represses cap-dependent translation during mitosis
}

\author{
Sihyeon $\mathrm{An}^{1}$ · Oh Sung Kwon ${ }^{1}$. Jinbae $\mathrm{Yu}^{1}$. Sung Key Jang ${ }^{1}$
}

Received: 22 March 2019 / Revised: 11 December 2019 / Accepted: 23 December 2019 / Published online: 6 February 2020

(c) The Author(s) 2020

\begin{abstract}
During mitosis, translation of most mRNAs is strongly repressed; none of the several explanatory hypotheses suggested can fully explain the molecular basis of this phenomenon. Here we report that cyclin-dependent CDK11/p58-a serine/threonine kinase abundantly expressed during $\mathrm{M}$ phase-represses overall translation by phosphorylating a subunit (eIF3F) of the translation factor eIF3 complex that is essential for translation initiation of most mRNAs. Ectopic expression of CDK11/p58 strongly repressed cap-dependent translation, and knockdown of CDK11/p58 nullified the translational repression during $\mathrm{M}$ phase. We identified the phosphorylation sites in eIF3F responsible for M phase-specific translational repression by CDK11/ p58. Alanine substitutions of CDK11/p58 target sites in eIF3F nullified its effects on cell cycle-dependent translational regulation. The mechanism of translational regulation by the $\mathrm{M}$ phase-specific kinase, CDK11/p58, has deep evolutionary roots considering the conservation of CDK11 and its target sites on eIF3F from C. elegans to humans.
\end{abstract}

Keywords CDK11/p58 · Translation initiation · eIF3F · Translational repression in M phase

\section{Abbreviations \\ CDK11 Cyclin-dependent kinase 11 \\ CCND3 Cyclin D3 \\ eIF3F Eukaryotic initiation factor $3 \mathrm{~F}$ \\ SUnSET Surface sensing of translation}

\section{Introduction}

Translation is the last step of gene expression, and regulation of gene expression at the translational level plays important roles in various biological processes owing to its rapid and reversible nature and the necessity of controlling gene expression spatially. Translation is a complex process that requires many protein and RNA participants $[1,2]$.

Electronic supplementary material The online version of this article (https://doi.org/10.1007/s00018-019-03436-3) contains supplementary material, which is available to authorized users.

Sung Key Jang

sungkey@postech.ac.kr

1 PBC, Department of Life Sciences, Pohang University of Science and Technology (POSTECH), Cheongam-ro 77, Nam-gu, Pohang-si, Gyeongsangbuk-do 37673, Republic of Korea
Translation initiation requires many translation factors and is the major regulation point.

Global regulation of gene expression often occurs at the translational level for general modulation of cellular physiology, because approximately $50 \%$ of cellular energy is consumed during translation and its related reactions [3, 4]. The best known example is stress-dependent repression of translation. Various stresses, such as amino acid starvation, ER overloading, oxidative stress, and viral infection, activate corresponding kinases that phosphorylate the alpha subunit of the translation initiation factor, eIF2, which loads the initiator tRNA (Met-tRNA ${ }_{i}{ }^{\mathrm{Met}}$ ) onto the 40S ribosomal subunit [5]. The eIF2 containing the phosphorylated alpha subunit sequesters eIF2B, which exchanges GDP for GTP on eIF2 for its activation. Sequestration of eIF2B inhibits eIF2-dependent Met-tRNA ${ }_{i}^{\text {Met }}$ binding to the $40 \mathrm{~S}$ ribosomal subunit $[6,7]$. As a consequence, global translation is repressed by various cellular stresses.

Another well-known example is translational regulation via mammalian target of rapamycin (mTOR). Activation of mTOR leads to the phosphorylation of eIF4E-binding protein 1 (4E-BP1), resulting in the dissociation of 4E-BP1 from the mRNA cap-binding protein eIF4E. Unphosphorylated 4E-BP1 sequesters eIF4E from eIF4F complex through a competitive binding to eIF4E, resulting in the inhibition of cap-dependent translation $[8,9]$. 
The third example of overall translational regulation is the cell cycle-dependent translational fluctuation. $\mathrm{M}$ phase is the final stage of the cell cycle wherein a cell divides into two daughter cells. Compared with cells in interphase, cells in $\mathrm{M}$ phase show drastic changes in many biological processes, such as inhibition of transcription and translation, chromosome condensation, nuclear envelope breakdown, and assembly of the mitotic spindle [10-12]. It is well established that the translation efficiencies of the most mRNAs are high in interphase but low in M phase [13, 14]. In this study, we investigated the molecular basis of global translational repression during $\mathrm{M}$ phase. Cell cycledependent translational regulation is required for promoting cell division and survival. For example, the expression of Emi1, an inhibitor of the anaphase-promoting complex (APC), is translationally repressed during mitosis, resulting in the activation of APC during M phase [15]. In contrast, some mRNAs are translationally activated during mitosis. For example, the IRES-dependent translation of Bcl-2 and CDK1 is enhanced during mitosis to prevent cell death caused by the activation of caspases [16].

Several mechanisms have been proposed to explain global translational repression during $\mathrm{M}$ phase. One proposed mechanism is through hypo-phosphorylation of eIF4E-binding protein 1 (4E-BP) during mitosis [17] since hypo-phosphorylated 4E-BP1 inhibits cap-dependent translation by interfering with the association of eIF4G to the cap-binding protein, eIF4E [18]. However, it was reported that 4E-BP1 is phosphorylated during mitosis directly by CDK1 [19] or indirectly through activation of the mTORC1 pathway by phosphorylation of the mTORC1-associated protein, raptor [20, 21]. Recently, the involvement of CDK1 in global translational repression was suggested by Dobrikov et al. [22]. The authors suggested that CDK1/cyclin B-dependent phosphorylation of eIF4G1 represses global translation during $\mathrm{M}$ phase by enhancing the interaction of eIF4A with eIF4G1. This enhanced interaction decreases the RNA-binding ability of the eIF4G1/eIF4A complex [22]. PKR, a stressresponsive kinase activated by double-stranded RNA, was also suggested to mediate translational repression during $\mathrm{M}$ phase [23]. However, mitotic translational repression was not fully restored by blocking the phosphorylation of eIF4G1 and eIF $2 \alpha[22,23]$. These results suggest the existence of an unknown mechanism by which translational repression occurs during $\mathrm{M}$ phase.

The cell cycle is a complex process that requires exquisite regulation of gene expression. In eukaryotes, the two major classes of factors-cyclin-dependent kinases (CDKs) and their positive regulator named cyclins-play key roles in controlling numerous changes during cell division. These evolutionarily conserved regulators are essential for managing cell cycle progression in simple unicellular organisms, such as yeasts, to complex multicellular organisms, such as mammals [10]. In humans, there are more than 20 types of CDKs. Among them, CDK1 to CDK11 are known to function stage-specifically during the G1, G1/S, S, G2, and $M$ phases [24]. CDK11, also known as PITSLRE kinase, has three isoforms that show peculiar expression patterns. Hereafter, the largest, mid-sized, and smallest isoforms of CDK11 are designated as CDK11/p110, CDK11/p58, and CDK11/p46, respectively. The CDK11 isoforms have a common C-terminal region containing the kinase domain. The $\mathrm{N}$-terminal regions of CDK11 isoforms differ from each other. CDK11/p110, which is expressed continuously during cell cycle, localizes in the nucleus and regulates RNA transcription and pre-mRNA splicing through its association with RNA polymerase II and cyclin L $[25,26]$. CDK11/ p58 is translated from the same mRNA as CDK11/p110. However, the translation of CDK11/p58 is directed by an IRES that resides in the coding region of CDK11/p110 using an alternative in-frame AUG codon during $M$ phase [27]. CDK11/p58 is known to facilitate $\mathrm{M}$ phase progression by promoting centrosome maturation and bipolar spindle formation $[28,29]$. Independent of cell cycle regulation, the CDK11/p58-cyclin D3 (CCND3) complex inhibits androgen receptor activity through phosphorylation [30]. CDK11/p46 is a truncated form of CDK11/p110 and CDK11/p58 that is through proteolytic cleavage by caspase- 3 during apoptosis and represses cap-dependent translation by phosphorylating eIF3F [31-35]. Thus far, no specific cyclin partner of CDK11/p46 activity has been found.

eIF3 is the largest translation initiation factor and is composed of 13 non-identical protein subunits that are named eIF3A to eIF3M (in mammals) [36]. eIF3 connects the 40S ribosomal subunit with the translation initiation factors that are associated with mRNAs (e.g., eIF4F complex and PABP) through direct interactions with eIF4G $[37,38]$ and the $40 \mathrm{~S}$ ribosomal subunit $[39,40]$. Moreover, eIF3 directly interacts with the multi-factor complex of eIF1-eIF2-eIF5 [41]. Through the interactions with translation factors and an mRNA, eIF3 facilitates the formation of the 48S preinitiation complex.

Translation initiation factors are related to cell proliferation and tumorigenesis. For example, activation of eIF4F complex is involved in tumorigenesis [42, 43], and glycosylation of eIF4G promotes cell proliferation [44]. Alterations in eIF3 subunit expression have been reported for many types of cancer cells, such as the overexpression of eIF3A, $\mathrm{B}, \mathrm{C}, \mathrm{H}, \mathrm{I}$, and $\mathrm{M}$, and under-expression of eIF3E and F [45]. These studies imply that the eIF3 subunits have various roles in cell proliferation. The expression of eIF3F is decreased in melanomas and pancreatic cancer. Furthermore, ectopic expression of eIF3F induces apoptosis and reduces protein synthesis, while knockdown of eIF3F enhances cell proliferation rates [46-49]. These results suggest that eIF3F modulates cell proliferation by repressing translation. 
In this study, we investigated the role of CDK11/p58, which is $\mathrm{M}$ phase-specifically expressed, in global translational repression during mitosis. Overexpression of CDK11/ p58 inhibited cap-dependent translation, and knockdown of CDK11 nullified the repression of cap-dependent translation during $\mathrm{M}$ phase. We also found that eIF3F is the molecular target of CDK11/p58 that is responsible for M phase-specific translational repression. Phosphorylation of Thr255 and/or Ser258 in eIF3F by CDK11/p58 resulted in global translational repression in $\mathrm{M}$ phase. Our findings suggest that the $\mathrm{M}$ phase-specific, IRES-dependent production of CDK11/p58 mediates global translational repression during $\mathrm{M}$ phase by phosphorylating the crucial translation factor, eIF3.

\section{Materials and methods}

\section{Construction of plasmids}

The plasmid, which was used for generation of the bicistronic reporter mRNA [50], was kindly provided by Dr. Peter Sarnow (Stanford University). To construct plasmids expressing Flag-tagged CDK11/p110, CDK11/p58, and CDK11/p46, different regions of the CDK11 gene were amplified by PCR from a plasmid containing the CDK11/ p110 gene, which was kindly provided by Dr. Susana Valente (The Scripps Research Institute). The primers used in the PCR were as follows: CDK11/p110 (forward: 5'-CCC AAGCTTCGATGGGTGATGAAAAGGAC-3'), CDK11/ p58 (forward: 5'-CGCAAGCTTATGAGTGAAGATGAA GAAC-3'), CDK11/p46 (forward: 5'-CGCAAGCTTGTG CCCGACTCCCCT-3'), and a common reverse primer (5'CCCTCTAGATCAGAACTTGAGGCTGAAG-3'). The amplified DNAs were digested with HindIII and XbaI and then ligated into the HindIII-XbaI site of pcDNA3.1-Flag. The plasmid containing the kinase-dead mutant, CDK11/ p58M, was generated by site-directed mutagenesis by mutating Asp224 to Asn in CDK11/p58 [51] using the following primers: forward (5'-CCGGCATCCTCAAGGTGGGTA ACTTCGGGCTGGCGCGGGAG-3') and reverse (5'-CTC CCGCGCCAGCCCGAAGTTACCCACCTTGAGGAT GCCGG-3').

Constructions of the plasmids, pcDNA3.1-Flag and pcDNA3.1-myc, were described previously [52]. To construct plasmids encoding for eIF3F and CCND3 (NM_003754 and NM_001760), the eIF3F and CCND3 genes were amplified by PCR using a human cDNA library (Clontech) with the following primers: eIF3F (forward: 5'-CCGGATCCATGGCCACACCGGCG-3' and reverse: 5'-CCTCTAGATCACAGGTTTACA AGTTTTTC-3'); CCND3 (forward: 5'-CCAAGCTTATGGAGCTGCTGTG$3^{\prime}$ and reverse: 5'-CCGCGGCCGCCTACAGGTGTATGG CTG-3'). The amplified eIF3F DNA was digested with
BamHI and $\mathrm{XbaI}$ and ligated into the BamHI-XbaI site of pcDNA3.1-Flag or pcDNA3.1-myc. The amplified CCND3 DNA was digested with HindIII and NotI and ligated into the HindIII-NotI site of pcDNA3.1-Flag. Plasmids encoding for the phosphomimetic and unphosphorylatable eIF3F constructs were generated by site-directed mutagenesis (Fig. 5a). To generate pcDNA3.1-Flag-eIF3F(D1D2) and pcDNA3.1Flag-eIF3F(A1A2), S46 and T119 in pcDNA3.1-Flag-eIF3F were mutated consecutively. pcDNA3.1-Flag-eIF3F_S46D and pcDNA3.1-Flag-eIF3F_S46A were generated by PCR mutagenesis using pcDNA3.1-Flag-eIF3F with the following primers: eIF3F_S46D (forward: 5'-CCCGCTGCGGCT CCAGCCTCAGACTCAGACCCTGCGGCAGCAGCG-3' and reverse: 5'-CGCTGCTGCCGCAGGGTCTGAGTC TGAGGCTGGAGCCGCAGCGGG-3') and eIF3F_S46A (forward: 5'-CCCGCTGCGGCTCCAGCCTCAGCCTCA GACCCTGCGGCAGCAGCG-3' and reverse: 5'-CGC TGCTGCCGCAGGGTCTGAGGCTGAGGCTGGAGC CGCAGCGGG-3'). pcDNA3.1-Flag-eIF3F(D1D2) and pcDNA3.1-Flag-eIF3F(A1A2) were generated by PCR mutagenesis using pcDNA3.1-Flag-eIF3F_S46D and pcDNA3.1-Flag-eIF3F_S46A, respectively, with the following primers: eIF3F(D1D2) (forward: 5'-GGTGCTGCCCGA GTTATCGGGGACCTGTTGGGAACTGTCGACAAA-3' and reverse: 5'-TTTGTCGACAGTTCCCAACAGGTCCCC GATAACTCGGGCAGCACC-3') and eIF3F(A1A2) (forward: 5'-GGTGCTGCCCGAGTTATCGGGGCCCTGTTG GGAACTGTCGACAAA-3' and reverse: 5'-TTTGTCGAC AGTTCCCAACAGGGCCCCGATAACTCGGGCAGC ACC-3'). pcDNA3.1-Flag-eIF3F(D3D4) and pcDNA3.1Flag-eIF3F(A3A4) were generated by PCR mutagenesis using pcDNA3.1-Flag-eIF3F with the following primers: eIF3F(D3D4) (forward: 5'-GAGTTGACCTGATCATGA AGGACTGCTTTGACCCCAACAGAGTGATTGGACT3' and reverse: 5'-AGTCCAATCACTCTGTTGGGGTCA AAGCAGTCCTTCATGATCAGGTCAACTC-3') and eIF3F(A3A4) (forward: 5'-GAGTTGACCTGATCATGA AGGCCTGCTTTGCCCCCAACAGAGTGATTGGACT3' and reverse: 5'-AGTCCAATCACTCTGTTGGGGGCA AAGCAGGCCTTCATGATCAGGTCAACTC-3').

\section{Synthetic siRNA}

The negative control siControl and siCDK11 were purchased from Bioneer. The sequence of siCDK11 has been previously described [30].

\section{Establishment of cell lines stably expressing eIF3F variants}

HeLa cells were cultivated in Dulbecco's modified Eagle's medium (DMEM; Gibco BRL) supplemented with $10 \%$ fetal bovine serum (Hyclone) and 1\% penicillin/streptomycin 
(Invitrogen) under $5 \% \mathrm{CO}_{2}$. To establish cell lines ectopically expressing eIF3F variants (eIF3F(WT), eIF3F(A1A2), or eIF3F(A3A4)), pcDNA3.1-Flag-eIF3F, pcDNA3.1-FlageIF3F(A1A2), or pcDNA3.1-Flag-eIF3F(A3A4) were transfected into HeLa cells with Lipofectamine 3000 (Invitrogen) according to the manufacturer's instruction. Control HeLa cells were transfected with the pcDNA3.1-Flag. Cells containing the plasmids were selected with $200 \mu \mathrm{g} / \mathrm{mL}$ of hygromycin B (AG Scientific).

\section{In vitro transcription and transfection}

To synthesize the 5 '-capped, bicistronic reporter mRNA $(\mathrm{RCF})$, in vitro transcription was performed using the $\mathrm{T} 7$ RNA polymerase in the presence of the $3^{\prime} \mathrm{O}-\mathrm{Me}-\mathrm{m}^{7} \mathrm{G}\left(5^{\prime}\right)$ $\operatorname{ppp}\left(3^{\prime}\right) \mathrm{G}$ (anti-reverse cap analog) and the bicistronic reporter plasmids that had been linearized by digestion with XbaI. Transfections of reporter mRNAs, synthetic siRNAs and plasmid DNAs were carried out using Lipofectamine 3000 (Invitrogen) according to the manufacturer's instruction.

\section{Measurement of the translation efficiencies of reporter genes}

To measure the efficiencies of cap-dependent and CrPV IRES-dependent translation, the indicated effector plasmids were transfected into $40 \%$ confluent HeLa cells grown in six-well plates. After $48 \mathrm{~h}$, cells were transfected with the bicistronic reporter mRNAs (RCF) and then incubated for $4 \mathrm{~h}$. The cells were treated with passive lysis buffer (Promega) and harvested. Renilla and firefly luciferase activities were measured using a dual-luciferase kit (Promega) according to the manufacturer's instruction.

\section{Synchronization of cells}

HeLa cells were synchronized at G1/S boundary or in M phase using the double thymidine or thymidine-nocodazole block methods, respectively [53]. Briefly, HeLa cells were cultivated to $40 \%$ confluence and then treated with $2 \mathrm{mM}$ thymidine (Sigma) for $16 \mathrm{~h}$. The cells were washed three times with PBS at $37{ }^{\circ} \mathrm{C}$ and then cultivated in fresh media for $8 \mathrm{~h}$. For synchronization of cells in interphase, cells were further cultivated in the presence of $2 \mathrm{mM}$ thymidine for $16 \mathrm{~h}$. For synchronization of cells in $\mathrm{M}$ phase, cells were further cultivated in the presence of $100 \mathrm{ng} / \mathrm{mL}$ nocodazole (Sigma) for $16 \mathrm{~h}$

Synchrony of cells was confirmed by flow cytometry analysis after staining the cells with propidium iodide. After synchronization, cells were trypsinized, collected by centrifugation, washed twice with cold PBS, and fixed in $70 \%$ methanol/distilled water for $1 \mathrm{~h}$ at $4{ }^{\circ} \mathrm{C}$. The cells were then precipitated by slow centrifugation, washed with cold PBS, and incubated with $0.2 \mathrm{mg} / \mathrm{mL}$ of RNaseA (Sigma) for $1 \mathrm{~h}$ at $37{ }^{\circ} \mathrm{C}$. The cells were incubated with $5 \mu \mathrm{g} / \mathrm{mL}$ propidium iodide (BioLegend) for $30 \mathrm{~min}$ at RT. Ten thousand cells from each sample were analyzed by flow cytometry using a Canto II instrument (Becton Dickinson) to determine DNA content as an indicator of synchrony.

\section{SUnSET}

HeLa cells were transfected with the indicated plasmids and cultivated on plates. After transfection, cells were synchronized in interphase or $\mathrm{M}$ phase as described above. After synchronization, cells were washed three times with PBS at $37{ }^{\circ} \mathrm{C}$ and cultivated in growth medium in the presence of $5 \mathrm{mM}$ puromycin (Sigma) for $15 \mathrm{~min}$. Newly synthesized proteins were detected by western blotting using an antipuromycin antibody.

\section{Immunoprecipitation, phos-tag PAGE, and western blotting}

HeLa cells were transfected with the indicated plasmids and cultivated on plates. At $48 \mathrm{~h}$ after transfection, cells were washed with cold PBS and harvested with ice-cold lysis buffer (0.1\% NP-40, $40 \mathrm{mM}$ HEPES-KOH $(\mathrm{pH}$ 7.5), $100 \mathrm{mM} \mathrm{KCl}, 1 \mathrm{mM}$ EDTA, $10 \mathrm{mM} \mathrm{NaF}, 10 \mathrm{mM}$ $\beta$-glycerophosphate, $2 \mathrm{mM} \mathrm{Na}_{3} \mathrm{VO}_{4}$, and $1 \mathrm{mM} \mathrm{PMSF}$ ). The cells were lysed by sonication, and cell debris was cleared by centrifugation. For immunoprecipitation, $300 \mu \mathrm{g}$ of wholecell extracts (WCEs) were incubated with $1 \mu \mathrm{g}$ of anti-myc antibody (GeneTex, GTX29106) and $10 \mu \mathrm{L}$ of Protein A agarose (Roche) at $4{ }^{\circ} \mathrm{C}$ for $2 \mathrm{~h}$ with constant rotation. The beads were collected by centrifugation and washed four times with fresh lysis buffer. WCEs and precipitates were resolved by SDS-PAGE and then transferred to PVDF membrane (Millipore). To separate phosphorylated from unphosphorylated proteins, Phos-tag (Wako; $50 \mu \mathrm{M}$ ) and $\mathrm{MnCl}_{2}$ $(50 \mu \mathrm{M})$ were added to the polyacrylamide gel [54]. The resolved proteins were analyzed by western blotting using the relevant antibodies. Band quantification was performed with Image J software [55]. The following primary antibodies were used for western blotting: control rabbit IgG (Santa Cruz, sc-2027), anti-Flag (Sigma, F1804), anti-Myc (GeneTex, GTX29106), anti-eIF3F (Rockland, 600-401-934), anti-CDK11 (Abcam, ab19393), anti-puromycin (Millipore, MABE343), and anti-GAPDH (AbD Serotec, 4699-9555).

\section{Statistical analysis}

All the statistical analyses were performed with GraphPad Prism 8.0. Data are expressed as means \pm standard deviations. To determine statistical significance, Student's $t$ tests 
(two-tailed) were performed and $p$ values $\leq 0.05$ were considered statistically significant.

\section{Results}

\section{Mitotic phase-specific kinase, CDK11/p58, represses cap-dependent translation}

We investigated whether various CDK11 isoforms can modulate translation efficiency. To test this, we transfected HeLa cells with plasmids encoding three different isoforms of CDK11 (p110, p58, and p46) (Fig. 1) and monitored capdependent and IRES-dependent translation of a reporter mRNA. We used a bicistronic mRNA (named RCF) containing CrPV IRES, which does not require a translation initiation factor for IRES-mediated translation [50], at the intercistronic region to direct the translation of the firefly luciferase (Fluc) gene (Fig. 1a). In contrast, translation of the Renilla luciferase (Rluc) gene in the first cistron occurs in a cap-dependent manner. Thus, relative luciferase activity of Rluc to Fluc represents cap-dependent translation efficiency. Expression of CDK11/p58 and co-expression of CDK11/ p58 and CCND3 significantly repressed cap-dependent
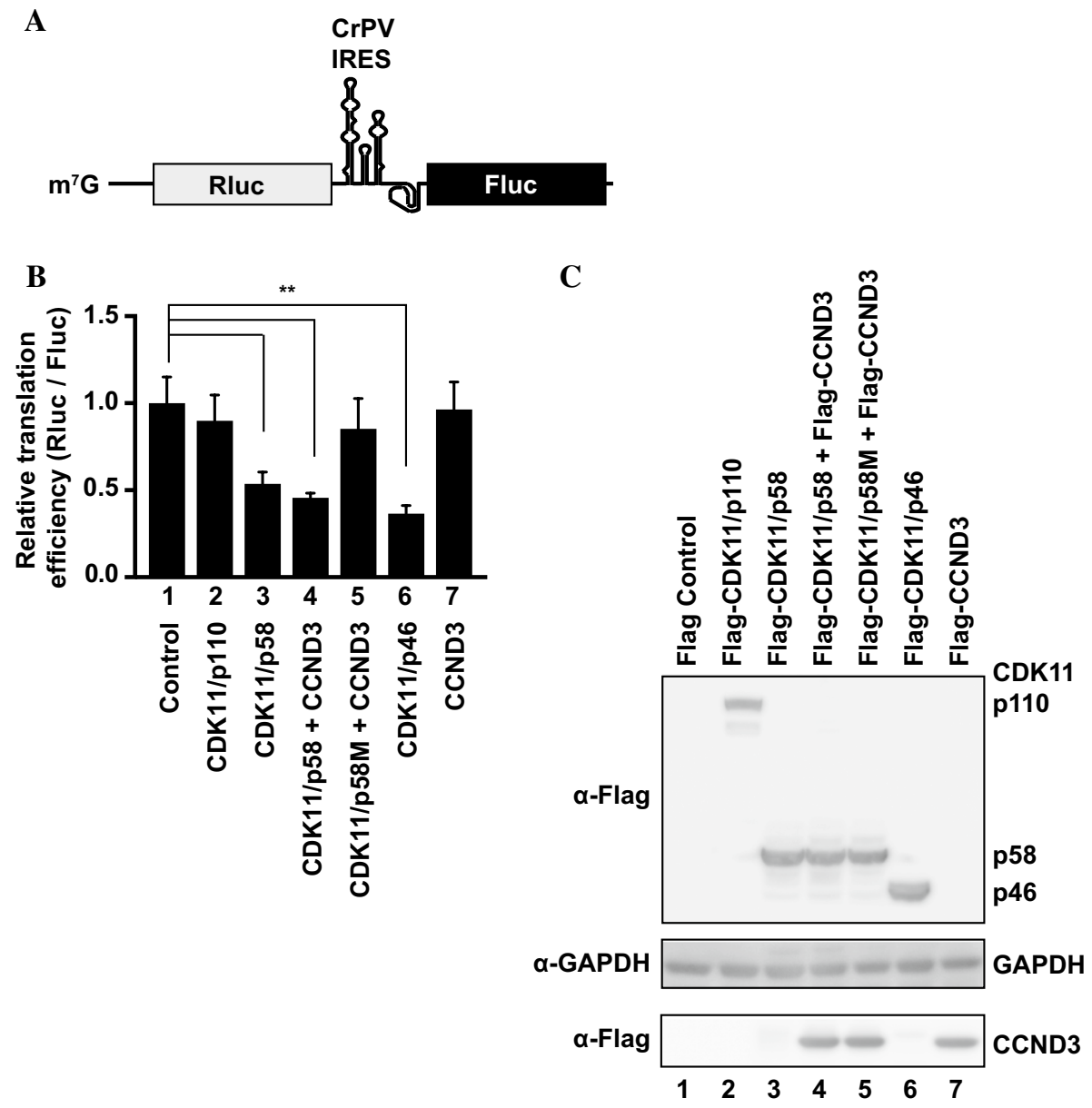

Fig. 1 CDK11/p58 represses cap-dependent translation. a Schematic diagram of a bicistronic reporter mRNA (RCF) containing the cap structure $\left(\mathrm{m}^{7} \mathrm{G}\right)$ at the $5^{\prime}$ end, Renilla luciferase (Rluc) gene at the first cistron, cricket paralysis viral (CrPV) IRES at the intercistronic region, and firefly luciferase (Fluc) gene at the second cistron. b Capand CrPV IRES-dependent translation of the reporter mRNA (RCF) in cells ectopically expressing CDK11 isoforms were monitored by measuring Renilla and firefly luciferase activities. At $48 \mathrm{~h}$ post-transfection of the corresponding plasmids encoding for effector CDK11 isoforms, HeLa cells were transfected with the bicistronic reporter RNA (RCF) that was synthesized by in vitro transcription. After $4 \mathrm{~h}$, cells were lysed, and luciferase activities were measured. The rela-

tive cap-dependent translation efficiencies, which were normalized to the CrPV IRES-dependent translation activity in each sample, are depicted. The cap-dependent translation activity in the control vectortransfected cells was set to 1 (lane 1). Experiments were repeated three times with duplicate samples. The columns and bars represent the means and \pm standard deviations, respectively. Asterisks $(* *)$ depict $P<0.005$, lanes 3, 4, and 6 compared with lane 1 . c The levels of ectopically expressed proteins (CDK11 isoforms and CCND3) in cells were monitored by western blot using an anti-Flag antibody. GAPDH levels were also monitored by western blot using an antiGAPDH antibody as an endogenous protein control 
translation, while expression of CCND3 alone showed no effect (Fig. 1b, lanes 3, 4, and 7). In contrast, CrPV IRESdependent translation was not affected by the expression of CDK11/p58 or co-expression of CDK11/p58 and CCND3.

To examine whether kinase activity of CDK11/p58 is required for repressing cap-dependent translation, we monitored the effect of ectopic expression of CDK11/p58Ma kinase-dead mutant of CDK11/p58 - on cap-dependent translation [51]. CDK11/p58M showed no effect on capdependent translation (Fig. 1b, lane 5). As reported previously [31, 32], CDK11/p46, the apoptosis-specific isoform of CDK11, repressed cap-dependent translation (Fig. 1b, lane 6). In contrast, ectopic expression of CDK11/p110, which is continuously expressed during cell cycle, showed no effect on cap-dependent translation (Fig. 1b, lane 2). These results indicate that CDK11/p58, which is expressed during $\mathrm{M}$ phase, inhibits cap-dependent translation, and that its kinase activity is required for translational repression. The levels of ectopically expressed CDK isoforms and CCND3 were monitored by western blotting (Fig. 1c).

\section{CDK11 is required for repressing global translation during mitosis}

We examined global translation during interphase and $\mathrm{M}$ phase by synchronizing HeLa cells in interphase (early $\mathrm{S}$ phase) by double thymidine block, or in $\mathrm{M}$ phase by thymidine-nocodazole block. Cell cycle synchronization was confirmed by a flow cytometry method (Fig. S1a). After synchronization of cells, we measured global translation rates by the surface sensing of translation (SUnSET) method. SUnSET allows the detection of newly synthesized proteins using puromycin, which is incorporated into elongating polypeptide chains. Newly synthesized proteins can be detected by western blotting using an anti-puromycin antibody [56]. To compare global translation rates, the band intensity of newly synthesized, puromycin-labeled proteins visualized by western blotting was normalized to the amount of total proteins visualized by Coomassie blue staining (Figs. 2a and S1b).

Global translation of cells synchronized in $\mathrm{M}$ phase was decreased by about $80 \%$ compared with cells synchronized in interphase (Fig. 2a). A previous study, which measured mitotic translation using SUnSET, showed similar repression patterns [22]. The global repression of translation that occurred in this study was likely attributed to two distinct mechanisms. Approximately half of the reduction is likely attributed to cells being in $\mathrm{M}$ phase, while the other half is likely attributed to the adverse effect of the microtubule inhibitor used during cell synchronization [15] (for details, refer to the discussion section).

As expected, the levels of CDK11/p58 were increased in cells arrested in M phase (Fig. 2b). To investigate the role of
CDK11 in mediating global translation during mitosis, we transfected siRNAs against CDK11 into HeLa cells and then synchronized cells at interphase or M phase (Fig. S2a). The global translation in the synchronized cells was monitored by the SUnSET method (Figs. 2c and S2b). Knockdown of CDK11 almost completely abolished $\mathrm{M}$ phase-specific expression of CDK11/p58 but partially reduced the level of CDK11/p110 (Fig. 2d). The discrepancy between levels of CDK11/p58 and CDK11/p110 after treatment of siRNAs targeting the same mRNA is likely attributed to the stability of these isoforms. It is noteworthy that CDK11/p58 exists only in $\mathrm{M}$ phase, indicating its labile character. In contrast, CDK11/p110 remains constant across the cell cycle, and thus, may not require fast degradation. The repression of global translation during mitosis was partially nullified when CDK11/p58 was depleted (Fig. 2c, compare lane 2 with 4). In contrast, translation of cells in interphase was not affected by CDK11/p58 depletion (Fig. 2c, compare lane 1 with 3). These results indicate that CDK11/p58 is required for global translational repression during mitosis since CDK11/p110 does not affect translation (Fig. 1b, lane 2).

\section{CDK11/p58 interacts with elF3F}

To explore how CDK11/p58 affects translation, we examined whether a substrate of CDK11/p58 is involved in translational regulation. Previous studies revealed that CDK11/ p46, the apoptosis-specific CDK11 isoform, directly interacts with and phosphorylates eIF3F to repress translation $[31,32]$. Thus, we examined whether other CDK11 isoforms can also interact with eIF3F by co-immunoprecipitation (Fig. 3). As expected, eIF3F co-precipitated CDK11/p46 (Fig. 3, lane 10). Interestingly, eIF3F also co-precipitated CDK11/p58, but not CDK11/p110 (Fig. 3, lanes 9 and 8). These results suggest that CDK11/p58 may phosphorylate eIF3F and affect translational regulation similar to CDK11/ p46.

\section{elF3F is phosphorylated by CDK11/p58 in mitotic phase}

Previous studies showed that eIF3F is phosphorylated during apoptosis by CDK11/p46 when cap-dependent translation is repressed [31, 32]. We examined the phosphorylation levels of endogenous eIF3F during interphase and $\mathrm{M}$ phase using Phos-tag - a method that can monitor the phosphorylation status of a protein by SDS-PAGE [54]. Phosphorylation of eIF3F in HeLa cells was increased by approximately 2.5 -fold during M phase (Fig. 4).

Since CDK11/p58 is specifically expressed during mitosis (Fig. 2b) and interacts with eIF3F (Fig. 3), we investigated whether CDK11/p58 is responsible for the M phasespecific phosphorylation of eIF3F. Knockdown of CDK11 
A

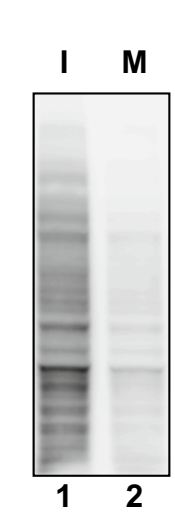

Interphase

Mitotic phase

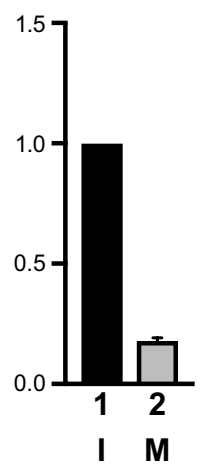

B

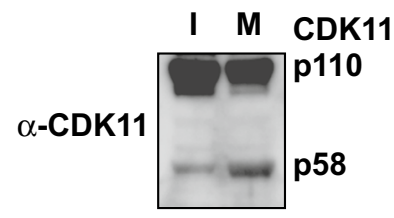

$\alpha-$ GAPDH $\square$ GAPDH

D
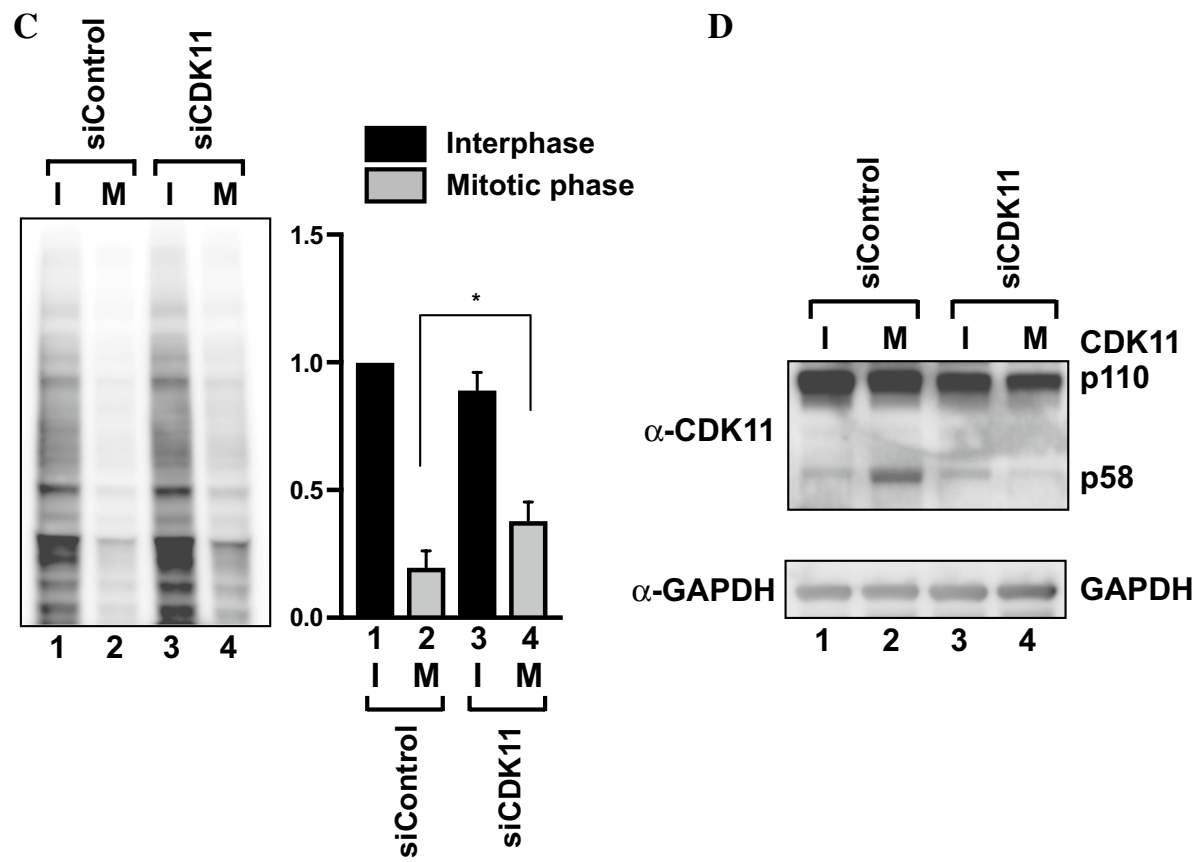

Fig. 2 Translation repression in M phase is nullified by knockdown of CDK11. a Global translation in interphase or M phase-arrested cells was monitored by western blotting using SUnSET (left panel). Synchronization of cells in either interphase or M phase was achieved as described in "Materials and methods". Puromycin was treated for $15 \mathrm{~min}$ after synchronization and the puromycin incorporation into newly synthesizing proteins was detected by western blotting using SUnSET. The band densities of newly synthesized proteins in interphase and $\mathrm{M}$ phase were measured and normalized to the amounts of total proteins measured by Coomassie blue staining (Fig. S1b). Relative values are depicted on the right panel. The sum of the band intensities from cells in interphase was set to 1 (lane 1). Experiments were repeated three times. Values are represented as the means and \pm standard deviations, respectively. b Protein levels of CDK11/p110 and CDK11/p58 in interphase- and $\mathrm{M}$ phase-synchronized cells were

drastically reduced the level of phosphorylated eIF3F in $M$ phase cells to that in interphase cells (Fig. 4b, compare lane 4 with 2 and 3). The result indicates that CDK11/p58 is responsible for the $\mathrm{M}$ phase-specific phosphorylation of

monitored by western blotting using an anti-CDK11 antibody. c The effect of CDK11 knockdown on cell cycle-dependent translation. HeLa cells were transfected with either a control siRNA (lanes 1 and 2) or a siRNA against CDK11 (lanes 3 and 4) $3 \mathrm{~h}$ before synchronization. Translation efficiencies were measured as in $\mathbf{a}$. Band densities of newly synthesized proteins in interphase and $\mathrm{M}$ phase were measured; relative values are depicted on the right panel. The sum of band intensities from cells in interphase treated with a control siRNA was set to 1 (lane 1). Experiments were repeated three times. The columns and bars represent the means and \pm standard deviations, respectively. Asterisk (*) depicts $P<0.05$, lane 4 compared with lane 2. d Protein levels of CDK11/p110 and CDK11/p58 in interphase- and M phasesynchronized cells treated with either a control siRNA (lanes 1 and 2) or an siRNA against CDK11 (lanes 3 and 4), were monitored by western blotting using an anti-CDK11 antibody

eIF3F. However, we cannot completely rule out the possibility of indirect phosphorylation of eIF3F by CDK11/p58 via an unidentified kinase activated by CDK11/p58 even though the indirect phosphorylation of eIF3F is less likely since 


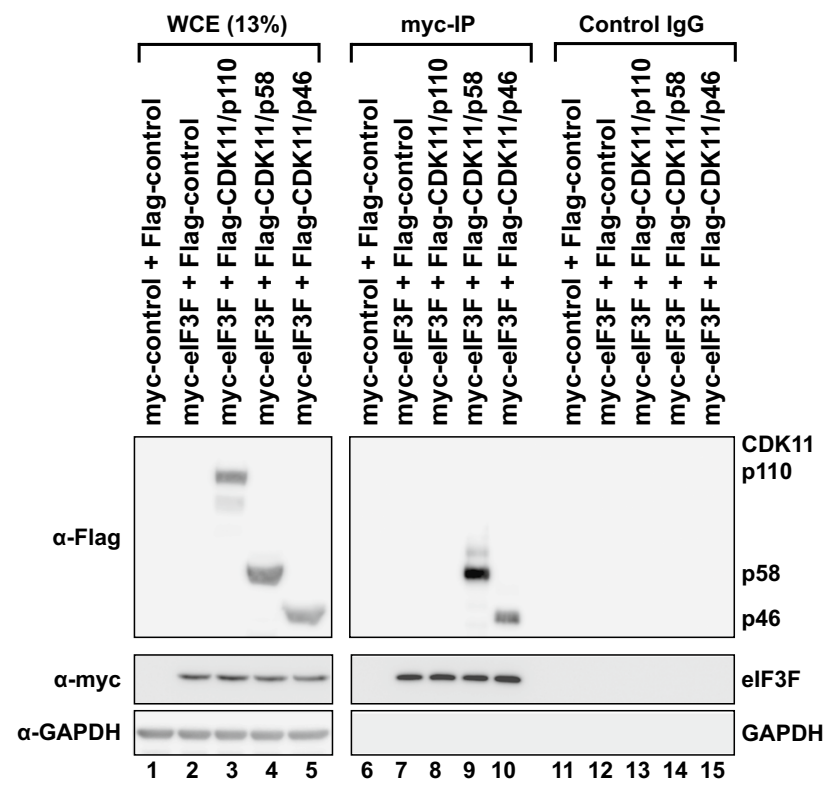

Fig. 3 CDK11/p58 interacts with eIF3F. Flag-CDK11 isoforms (p110, p58, and p46) and myc-eIF3F were co-transfected to HeLa cells. The myc-eIF3F was immunoprecipitated using an anti-myc antibody-conjugated protein A agarose resin (lanes 6-10). Non-specific interactions were monitored using an anti-rabbit antibody-conjugated protein A agarose resin (control, lanes 11-15). Protein levels of CDK11 isoforms and eIF3F were monitored by western blotting using anti-Flag and anti-myc antibodies, respectively. GAPDH levels were monitored by western blotting using an anti-GAPDH antibody as an endogenous protein control

CDK11/p58 associates with eIF3F (Fig. 3). It is worth to note that $7-10 \%$ of eIF3F proteins are phosphorylated in the control interphase cells and that similar amounts of eIF3F proteins are phosphorylated in both interphase and $\mathrm{M}$ phase of CDK11 knockdown cells (Fig. 4). The results suggest that the hyper-phosphorylation of eIF3F in M phase is solely attributed to CDK11/p58 and that the basal phosphorylation of eIF3F, which remains at the same level across the cell cycle in CDK11 knockdown cells (Fig. 4b), is likely executed by an unknown kinase(s) other than CDK11.

\section{Phosphorylation of elF3F represses cap-dependent translation}

A previous study revealed that Ser46 and Thr119 are the CDK11/p46-directed phosphorylation sites in eIF3F [32]. However, we speculated that CDK11/p58 might phosphorylate different residues since substrate specificity of CDKs is often determined by the cyclin associated with the particular CDK [57]. A proteome analysis of cell cycle-dependent phosphorylation revealed that two residues in eIF3F (Thr255 and Ser258) are specifically phosphorylated during $\mathrm{M}$ phase even though the kinase responsible for their phosphorylation is unknown [58]. We tested whether CDK11/p58, an M

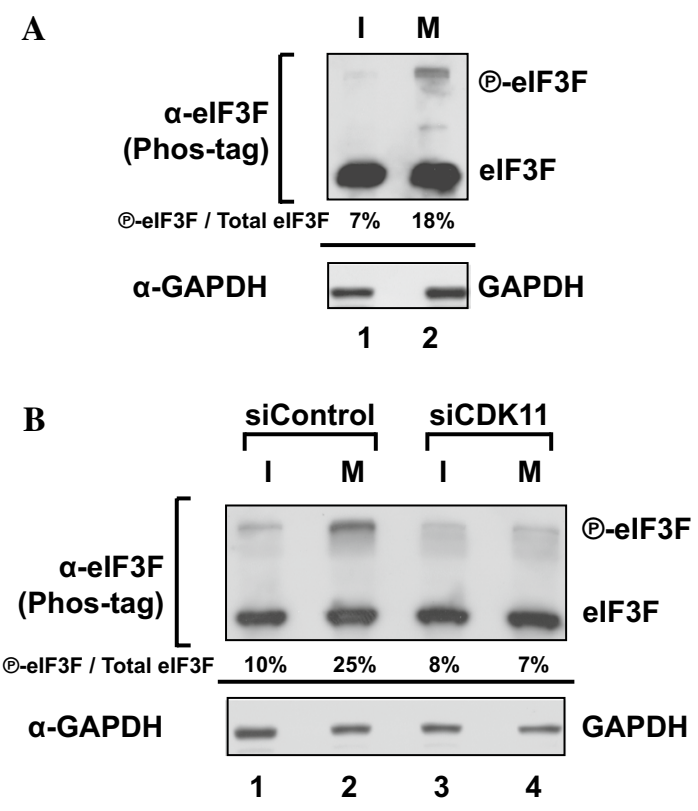

Fig. 4 Endogenous eIF3F is phosphorylated by CDK11/p58 during $\mathrm{M}$ phase. a The phosphorylation levels of endogenous eIF3F in interphase- and $\mathrm{M}$ phase-synchronized HeLa cells were measured by western blotting using Phos-tag SDS-PAGE. Slower migration of phosphorylated eIF3F in Phos-tag SDS-PAGE results in separation of fast-migrating under-phosphorylated and slow-migrating hyperphosphorylated eIF3F (p)-eIF3F) bands in the gel. Protein levels of $\mathrm{p}$-eIF3F and eIF3F were detected by western blotting using an anti-eIF3F antibody. The ratios of (p-eIF3F/total eIF3F are depicted. The levels of GAPDH were monitored as a loading control. b Phosphorylation levels of endogenous eIF3F in interphase- or M phasesynchronized HeLa cells with (lanes 3 and 4) or without knockdown (lanes 1 and 2) of CDK11 were monitored by western blotting using Phos-tag SDS-PAGE. Protein levels of (p)-eIF3F and eIF3F were detected by western blotting using an anti-eIF3F antibody. The ratios of (p)-eIF3F/total eIF3F are depicted. The levels of GAPDH were monitored as a loading control

phase-specific kinase, is responsible for the phosphorylation of these residues of eIF3F. For this purpose, we constructed four eIF3F mutants [eIF3F(A1A2), eIF3F(D1D2), eIF3F(A3A4), and eIF3F(D3D4)] (Fig. 5a): eIF3F(A1A2) contains substitution mutations from Ser46 and Thr119 to unphosphorylatable alanines (S46A and T119A); eIF3F(D1D2) contains substitution mutations from Ser46 and Thr119 to phospho-mimetic aspartic acids (S46D and T119D); eIF3F(A3A4) contains substitution mutations from Thr255 and Ser258 to unphosphorylatable alanines (T255A and S258A); eIF3F(D3D4) contains substitution mutations from Thr255 and Ser258 to phospho-mimetic aspartic acids (T255D and S258D).

Wild-type eIF3F [eIF3F(WT)] and eIF3F mutants (Fig. 5a) were transfected into HeLa cells and expressed at similar levels (Fig. 5c). Cap- and CrPV IRES-dependent translation in these cells were monitored using the CrPV bicistronic reporter mRNA, RCF (Fig. 1a). Expression 
A

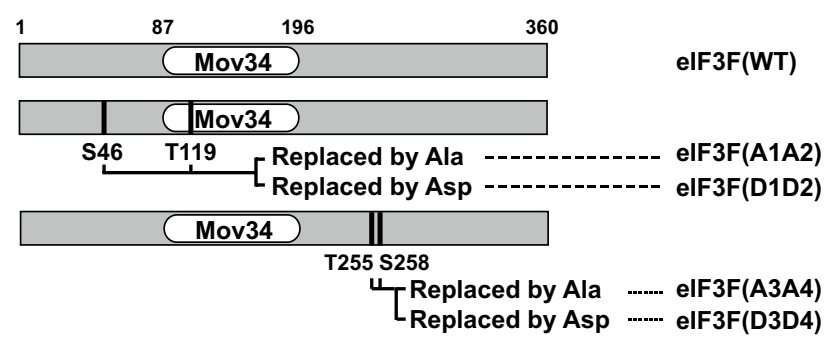

B

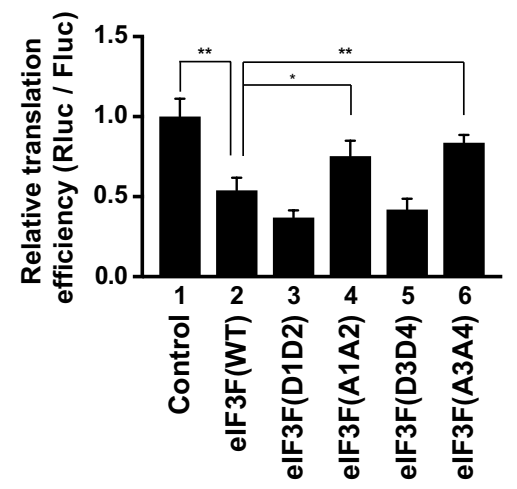

C

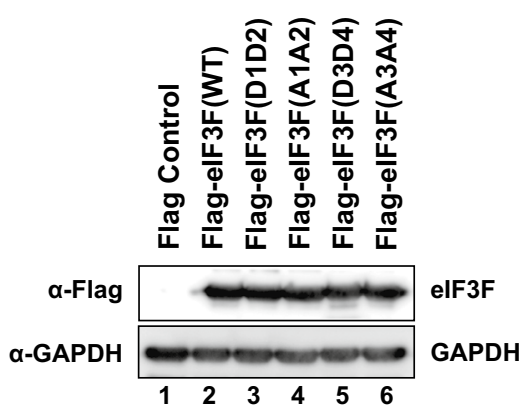

Fig. 5 Unphosphorylatable mutants of eIF3F do not repress translation. a Schematic diagrams of phospho-mimetic mutants [eIF3F(D1D2) and eIF3F(D3D4)], and unphosphorylatable mutants [eIF3F(A1A2) and eIF3F(A3A4)] of eIF3F. b The effects of ectopic expression of $\operatorname{eIF} 3 \mathrm{~F}(\mathrm{WT})$ and its derivatives on cap-dependent translation were monitored as described in Fig. 1 except that effector plasmids encoding eIF3F derivatives instead of CDK11 isoforms were used. The relative cap-dependent translation efficiencies, which were normalized to CrPV IRES-dependent translation activity in each sample, are depicted. The cap-dependent translation activity in control vector-transfected cells was set to 1 (lane 1). Experiments were repeated three times with duplicate samples. The columns and bars represent the means and \pm standard deviations, respectively. Asterisk (*) depicts $P<0.05$, lane 4 compared with lane 2 . Asterisks (**) depict $P<0.005$, lane 6 compared with lane 2 . c The levels of ectopically expressed proteins (eIF3F and its derivatives) in cells were monitored by western blotting using an anti-Flag antibody. The level of GAPDH protein was also monitored using an anti-GAPDH antibody as an endogenous protein control

of wild-type eIF3F reduced cap-dependent translation by $40 \%$ (Fig. 5b, compare lane 1 with 2). Expression of the phospho-mimetic mutants of eIF3Fs [eIF3F(D1D2) and eIF3F(D3D4)] further reduced cap-dependent translation
(Fig. 5b, compare lane 2 with 3 and 5). In contrast, expression of the unphosphorylatable eIF3F mutants [eIF3F(A1A2) and $\operatorname{IF} 3 \mathrm{~F}(\mathrm{~A} 3 \mathrm{~A} 4)]$ partially nullified the translation repression by eIF3F (Fig. 5b, compare lane 2 with 4 and 6). These data indicate that phosphorylation of Ser46, Thr119, Thr255, and/or Ser258 in eIF3F is involved in repressing cap-dependent translation. CrPV IRES-dependent translation was not affected by the ectopic expression of eIF3F variants.

\section{CDK11/p58 phosphorylates Thr255 and/or Ser258 of elF3F}

To investigate which amino acid residues are phosphorylated by CDK11/p58, we co-transfected the plasmids expressing eIF3F variants with those expressing CDK isoforms and then monitored cap- and IRES-dependent translation using the CrPV bicistronic reporter mRNA (Fig. 6). As shown in Fig. 1b, expression of CDK11/p58 together with CCND3 reduced cap-dependent translation (Fig. 6a, compare lane 1 with 5). Similarly, co-expression of wild-type eIF3F and CDK11/p58 together with CCND3 further reduced capdependent translation (Fig. 6a, compare lane 5 with 6). Coexpression of eIF3F(A1A2) and CDK11/p58 together with CCND3 reduced cap-dependent translation to the same level as wild-type eIF3F (Fig. 6a, compare lane 5 with 6 and 7). The results indicate that eIF3F(A1A2) was phosphorylated by CDK11/p58, which demonstrates that Ser46 and Thr119 of eIF3F are not targeted by CDK11/p58. In contrast, coexpression of eIF3F(A3A4) and CDK11/p58 together with CCND3 did not further reduce cap-dependent translation from the level observed by transfection of CDK11/p58 with CCND3 (Fig. 6a, compare lane 5 with 8). Thus, phosphorylation of eIF3F(A3A4) by CDK11/p58 did not occur, which demonstrates that Thr255 and/or Ser258 of eIF3F are the target sites for CDK11/p58.

As a control, we performed co-expression experiments with CDK11/p46. As previously reported [32], coexpression of eIF3F(A1A2) and CDK11/p46 did not further reduce cap-dependent translation from the expression observed with CDK11/p46 alone (Fig. 6a, compare lane 9 with 11). This indicates that CDK11/p46 did not phosphorylate eIF3F(A1A2), which demonstrates that Ser46 and Thr119 of eIF3F are the target sites for CDK11/p46. In contrast, co-expression of eIF3F(A3A4) and CDK11/ p46 reduced cap-dependent translation to the same level as wild-type eIF3F (Fig. 6a, compare lane 9 with 10 and 12). Thus, eIF3F(A3A4) was phosphorylated by CDK11/p46, demonstrating that Thr255 and Ser258 are not targeted by CDK11/p46. These data are consistent with the previous report [32]. Taken together our results suggest that CDK11/ p58 represses cap-dependent translation by phosphorylating the M phase-specific phosphorylation sites (Thr255 and/or 
A
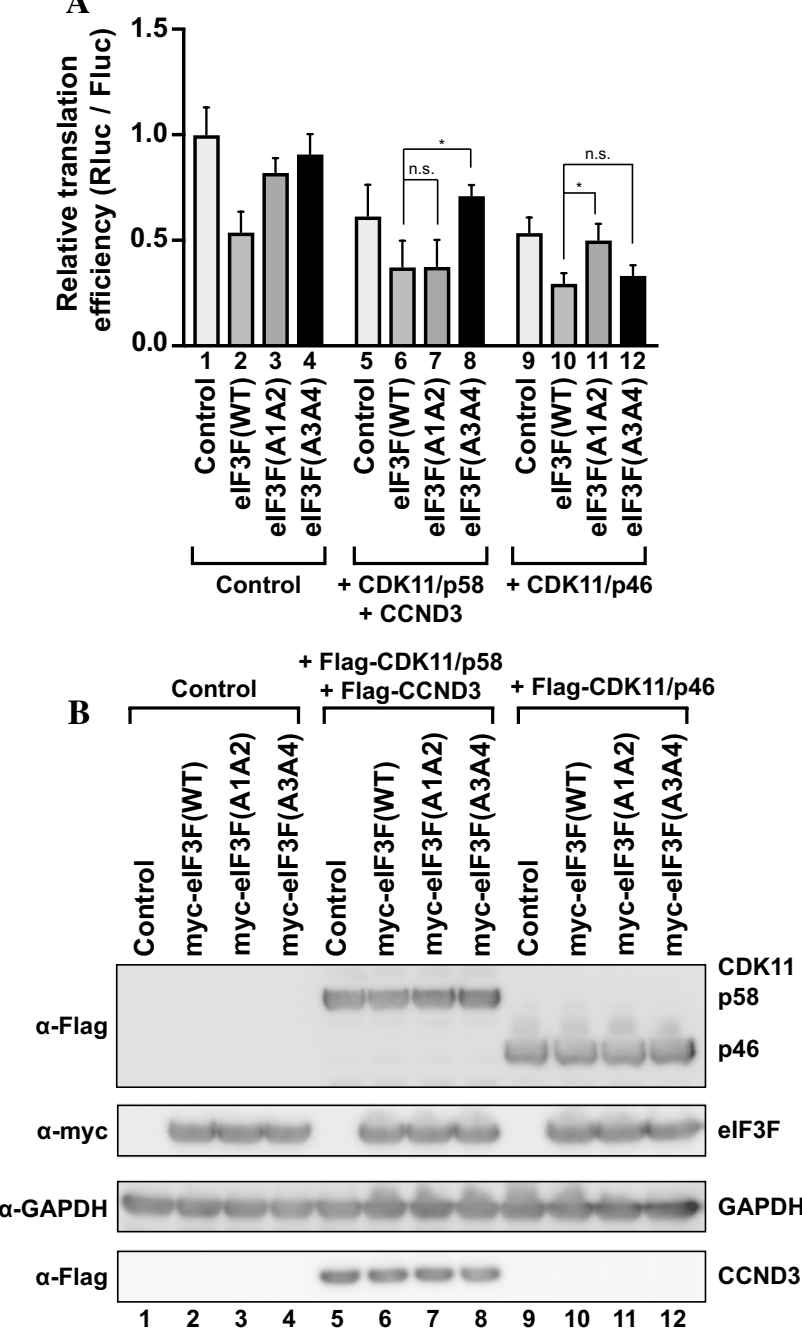

Fig. 6 CDK11/p58 phosphorylates Thr255 and/or Ser258 on eIF3F. a $\operatorname{IF} 3 \mathrm{~F}(\mathrm{~A} 3 \mathrm{~A} 4)$ nullifies the cap-dependent translation repression by CDK11/p58, but eIF3F(A1A2) nullifies the cap-dependent translation repression by CDK11/p46. Plasmids encoding Flag-CDK11/p46, Flag-CDK11/p58 plus Flag-CCND3, myc-eIF3F, or its derivatives were co-transfected into HeLa cells as indicated. The effects of coexpression of eIF3F derivatives and CDK11 isoforms on cap-dependent translation were monitored as described in Fig. 1, except that the effector plasmids encoding both eIF3F derivatives and CDK11 isoforms were used. The relative cap-dependent translation efficiencies, which were normalized to CrPV IRES-dependent translation activity in each sample, are depicted. The cap-dependent translation activity in control vector-transfected cells was set to 1 (lane 1). Experiments were repeated three times with duplicate samples. The columns and bars represent the means and \pm standard deviations, respectively. Asterisk (*) depicts $P<0.05$, lane 8 compared with lane 6, and lane 11 compared with lane $10 ; n$.s. non-significant $(P>0.05)$. b The levels of ectopically expressed proteins (CDK11 isoforms, eIF3F derivatives, and CCND3) in cells were monitored by western blotting using anti-Flag and anti-myc antibodies. GAPDH levels were monitored using an anti-GAPDH antibody as an endogenous protein control
Ser258) of eIF3F, and that the CDK11/p58- and CDK11/ p46-directed phosphorylation sites differ from each other.

We investigated whether the CDK11/p58-dependent phosphorylation of eIF3F affects eIF3 complex formation using a co-immunoprecipitation method. We performed co-immunoprecipitation experiments after ectopic expressions of two components of the eIF3 complex (Fig. S5a-c). Alternatively, we performed co-immunoprecipitation experiments after ectopic expression of one of the eIF3F variants to monitor eIF3 complex formation with the endogenous components of eIF3 (Fig. S5d). The results indicate that both phosphorylated [reflected by phospho-mimetic mutants eIF3F(D3D4)] and unphosphorylated eIF3F [reflected by unphosphorylatable mutants eIF3F(A3A4)] are incorporated into the eIF3 complex to the same extent. It is noteworthy that eIF3B, which does not directly interact with eIF3F in the eIF3 complex [59], was also co-precipitated with eIF3F variants to the same extent (Figs. S5a and S5d). Therefore, we conclude that the effect of eIF3F phosphorylation on translation is not attributed to changes in the efficiency of eIF3 complex formation.

To further investigate the presence of phosphorylated eIF3F in the eIF3 complex, we performed sucrose gradient analyses with HeLa cells synchronized at the interphase or mitotic phase (Fig. S6). As expected, eIF3B and eIF3F were mainly enriched in two fractions where eIF3 complex (fraction A) and the free forms of eIF3 components (fraction D) migrated during centrifugation (Fig. S6a). We analyzed the phosphorylated form of eIF3F in fractions A-D using Phos-tag SDS-PAGE. To our surprise, the phosphorylated eIF3F was not enriched in either fraction A or D. Instead, the phosphorylated eIF3F was enriched in fraction $\mathrm{B}$ having intermediate sedimentation velocity between the eIF3 complex and free eIF3F (Fig. S6c). This may indicate that the phosphorylated eIF3F composes an immature eIF3 complex which is lighter than the complete eIF3 complex (see below).

\section{Expression of the unphosphorylatable elF3F(A3A4) mutant nullifies $M$ phase-specific translational repression}

We further investigated the effects of eIF3F phosphorylation by CDK11/p58 on M phase translation using newly established HeLa cell lines ectopically expressing either wild-type eIF3F [eIF3F(WT)] or unphosphorylatable eIF3F mutants [eIF3F(A1A2) and eIF3F(A3A4)] (Figs. 7, 8). We synchronized the HeLa cells expressing eIF3F variants at interphase or $\mathrm{M}$ phase by chemical treatments. The synchronization of cells was monitored by flow cytometry (Fig. S3a). The global translation level of the cells in interphase and $\mathrm{M}$ phase was monitored by western blotting using the SUnSET method (Fig. 7a) and normalized to the total protein level in the cell extracts (Figs. $7 \mathrm{~b}$ and 


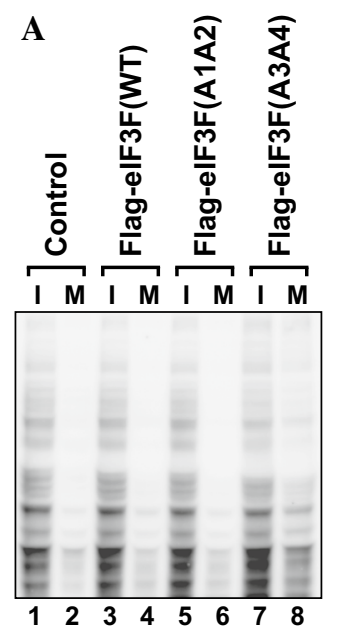

B
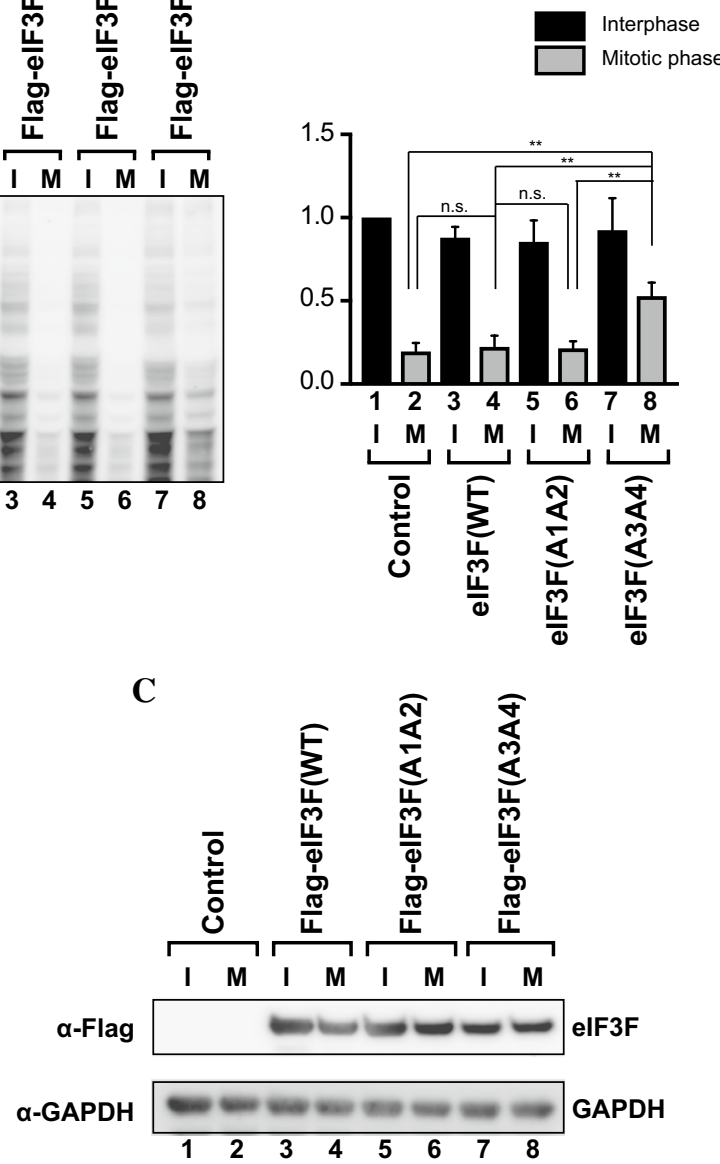

Fig. 7 Phosphorylation of Thr255 and/or Ser258 in eIF3F is required for $\mathrm{M}$ phase-specific translational repression. HeLa cell lines ectopically expressing eIF3F(WT), eIF3F(A1A2), or eIF3F(A3A4) were established as described in "Materials and methods". a Global translation of the established cells, which were synchronized in interphase (I) or M phase (M), was monitored by western blotting using the SUnSET method. b Band densities of newly synthesized proteins in panel (a) were measured and normalized to the amount of total proteins (Fig. S3b). The relative values are depicted as the sum of normalized band intensities in interphase cells established with a control vector is set to 1 . Experiments were repeated three times. The columns and bars represent the means and \pm standard deviations, respectively. c The levels of Flag-eIF3F(WT), Flag-eIF3F(A1A2), and Flag-eIF3F(A3A4) in the established cells in interphase- and $\mathrm{M}$ phase-synchronized cells were monitored by western blotting using an anti-Flag antibody. GAPDH levels were monitored using an antiGAPDH antibody as an endogenous protein control

S3c). Translation levels of the cells in interphase were similar irrespective of the expression of wild-type eIF3F or unphosphorylatable mutant eIF3Fs (Fig. 7b, compare lanes 1, 3, 5 and 7). Unlike the cells transiently expressing eIF3F variants, wherein cap-dependent translation was repressed by the ectopic expression of eIF3 variants (Fig. 5), the stable cell lines expressing eIF3F variants did not show apparent inhibition of global protein synthesis during interphase. This is likely because the modulation of translation by eIF3F variants during interphase is already reflected in the amounts of total proteins.

A striking difference in global translation was observed in M phase-arrested cells expressing eIF3F(A3A4), which cannot be phosphorylated by CDK11/p58 (Fig. 7a, compare lanes 2, 4, 6, and 8). The level of overall translation in cells in M phase expressing eIF3F(A3A4) was twofold higher than that in $\mathrm{M}$ phase cells expressing wild-type eIF3F or eIF3F(A1A2) (Fig. 7b, compare lane 8 with 4 and 6).

Even though translational repression in M phase cells, synchronized by nocodazole treatment, was partially nullified by the expression of eIF3F(A3A4), nocodazole induces stress-related translational inhibition that obscures the magnitude of translation repression in $\mathrm{M}$ phase [60]. Therefore, we explored an alternative approach to investigate the $\mathrm{M}$ phase-specific translational repression mediated by the phosphorylation of eIF3F under normal conditions. To minimize the external stresses during $\mathrm{M}$ phase, we synchronized cells at G1/S boundary by double thymidine block and resumed cell cycle progression by removing the compound as described previously [53]. The amount of DNA per cell was monitored by flow cytometry at various time points after the resumption of cell cycle progression (Fig. S4a). Most cells were in G2 phase at $6 \mathrm{~h}$ after the cell cycle resumption, and the majority of cells were in $M$ phase at $9 \mathrm{~h}$ after the cell cycle resumption. Most cells were in G1 phase at 10 and $12 \mathrm{~h}$ after the cell cycle resumption (Fig. S4a). As expected, the level of CDK11/p58 was the highest in cells at $9 \mathrm{~h}$ after the cell cycle resumption when the population of $\mathrm{M}$ phase cell is the highest (Fig. 8c).

We monitored the global translation levels of control, eIF3F(WT)-expressing, and eIF3F(A3A4)-expressing cells at various time points after cell cycle resumption by western blotting using the SUnSET method (Fig. 8a). The amounts of newly synthesized proteins at each time point were normalized to the amounts of total proteins measured by Coomassie blue staining (Fig. S4b), and the relative translational efficiencies at various time points after cell cycle resumption are depicted as a graph (Fig. 8b). The global translation level of $\mathrm{M}$ phase cells decreased to about 50\% compared with interphase cells in control and eIF3F(WT)-expressing cells. In contrast, the global translation level of $\mathrm{M}$ phase cells remained the same as interphase cells in eIF3F(A3A4)-expressing cells (Fig. 8b). The data indicate that translation is globally repressed about $50 \%$ in M phase cells and that phosphorylation of Thr255 and/or Ser258 in eIF3F by CDK11/p58 plays a major role in the $\mathrm{M}$ phase-specific translational repression. 
A

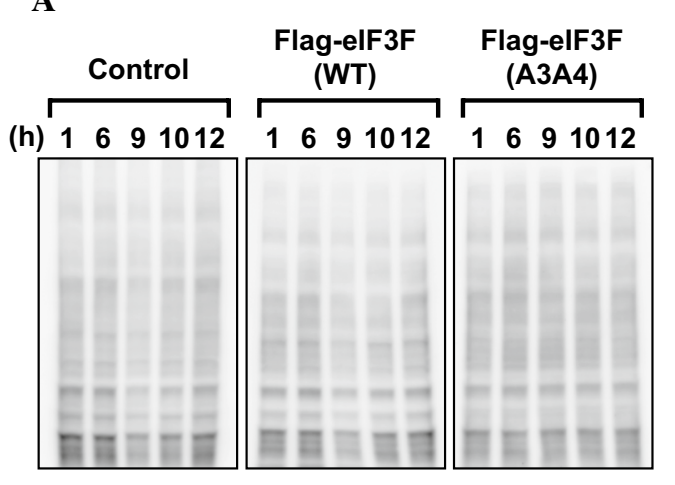

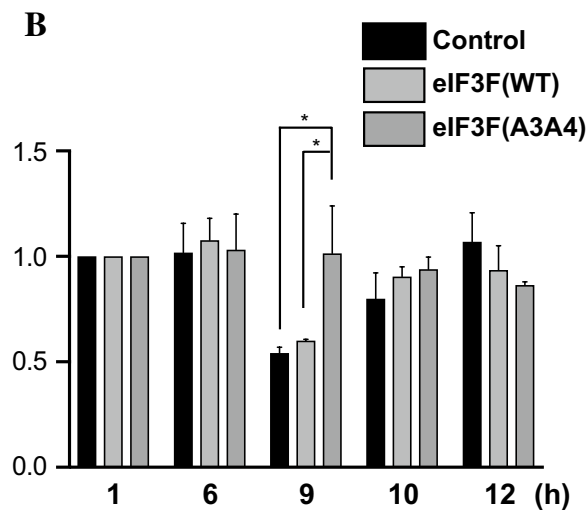

C
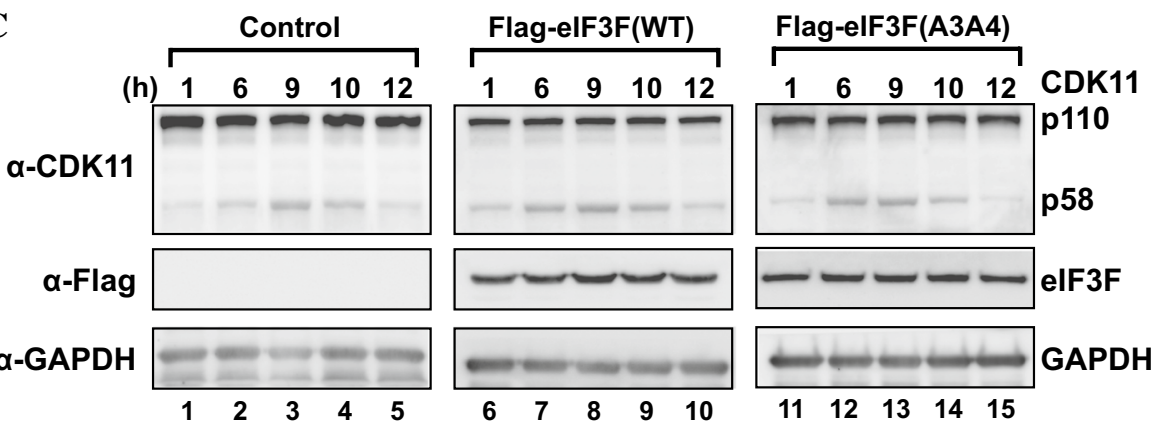

Fig. 8 Unphosphorylatable eIF3F(A3A4) completely nullifies M phase-specific translational repression. a HeLa cells ectopically expressing eIF3F variants were synchronized at G1/S boundary by double thymidine block and resumed cell cycle progression by removing the compound. Cells were harvested at the indicated time points after cell cycle resumption, and the global translation activity of cells was monitored by western blotting using the SUnSET method. b Band densities of newly synthesized proteins in a were measured and normalized to the amount of total proteins (Fig. S4b).

\section{Discussion}

Conventional studies on cell cycle-dependent translational regulation $[13,14]$ and genome-wide analysis of mRNAs that are translated at specific cell cycle phases revealed that cap-dependent translation generally decreases in $\mathbf{M}$ phase, while translation of some mRNAs continues, or even increases, in $\mathrm{M}$ phase [15]. In this study, we sought to understand the molecular basis of $\mathrm{M}$ phase-specific translational inhibition. We found that an isoform of CDK11 (CDK11/ p58), which exists in large amounts only during $M$ phase, inhibits cap-dependent translation through the phosphorylation of Thr255 and/or Ser258 in eIF3F, a subunit of eIF3. The co-immunoprecipitation of CDK11/p58 and eIF3F (Fig. 3) and the synergistic inhibition of cap-dependent translation by co-expression of these proteins (Fig. 6) indicate that CDK11/p58 directly phosphorylates eIF3F.

Even though several functions of CDK11/p58 during $M$ phase have been suggested, none of them revealed that CDK11/p58 functions in translational regulation.
The relative values are depicted as the sum of normalized band intensities of each cell line at $1 \mathrm{~h}$ after cell cycle resumption is set to 1 . Experiments were repeated three times. The columns and bars represent the means and \pm standard deviations, respectively. $\mathbf{c}$ The levels of CDK11/p110, CDK11/p58, Flag-eIF3F(WT), and Flag-eIF3F(A3A4) in the established cells were monitored by western blotting using antiCDK11 and anti-Flag antibodies. GAPDH levels were monitored using an anti-GAPDH antibody as an endogenous protein control

Thus, we uncovered a novel function of CDK11/p58 in modulating general translation during $\mathrm{M}$ phase. A previous study showed that CDK11/p46 produced in apoptotic cells represses translation by phosphorylating eIF3F [32]. However, the CDK11/p46-mediated phosphorylation sites in eIF3F (Ser46 and Thr119) are different from the CDK11/ p58-mediated phosphorylation sites (Thr255 and/or Ser258) (Fig. 6). The difference in residues targeted by CDK11 isoforms (CDK11/p46 and CDK11/p58) is likely attributed to the extended N-terminal region of CDK11/p58 (50 amino acids) compared with CDK11/p46 and/or to the cyclin D3 associated with CDK11/p58, which facilitates the kinase activity of CDK11/p58 [30, 61].

In this study, we demonstrated that the mitotic phosphorylation of eIF3F by CDK11/p58 leads to translational repression (Figs. 7, 8). We also showed that the phosphorylation of eIF3F does not block its interaction with at least some of the eIF3 components (Fig. S5). Moreover, we found that the phosphorylated eIF3F has a sedimentation velocity between eIF3 complex and free eIF3F (Fig. S6). 
Considering these phenomena, we speculate three plausible mechanisms of translational repression by phosphorylated eIF3F. (1) Phosphorylated eIF3F may compose an immature-nonfunctional eIF3 complex lacking some of eIF3 subunits, which blocks completion of eIF3 complex formation. According to a recently solved structure of the mammalian eIF3 complex, eIF3F is located in the center of the sevenhelix bundle composed of the C-terminal $\alpha$-helices of eIF3C, E, F, H, K and L [59]. In addition, it was suggested that the eIF3A/F/M subcomplex serves as an initial module for helix bundle formation through a study of the Neurospora crassa eIF3 complex [62]. Therefore, it is likely that eIF3F plays an important role in the initial step of eIF3 complex formation. Phosphorylated eIF3F seems to facilitate the formation of immature-nonfunctional eIF3 complex since the phosphorylated eIF3F does not exist in free form at both interphase and $M$ phase as shown in the fraction D of Fig. S6. (2) Phosphorylated eIF3F may make a complex with an unknown protein, which in turn induces translational repression during $M$ phase. It should be noted that translational inhibition during $\mathrm{M}$ phase reaches up to $50 \%$ (Fig. $8 \mathrm{~b}$ ) but the $\mathrm{M}$ phase-specific phosphorylation of eIF3 reaches only up to $15 \%$ (Fig. 4), and that a homologous gene of eIF3F is not present in yeast (S. cerevisiae), which suggests that eIF3F is not essential for translational activation by eIF3. Moreover, overproduction of eIF3F inhibits cap-dependent translation [32] (also see Fig. 5), and knockdown of eIF3F increases cell proliferation [46]. It is noteworthy that an analogous translational repression has been documented in the interferon (IFN)- $\gamma$-activated inhibitor translation (GAIT) system even though the GAIT system functions for specific mRNAs. A ribosomal protein L13a is phosphorylated by DAPK-ZIPK kinase axis and released from the 60S ribosomal subunit about $16 \mathrm{~h}$ after IFN- $\gamma$ stimulation, and then the phosphorylated L13a associates with pre-GAIT complex to form the functional GAIT complex which represses translation of specific mRNAs, such as human ceruloplasmin mRNA, containing a GAIT element in the $3^{\prime}$ untranslated region [63, 64]. (3) The immature eIF3 complex described in speculation (1) may associate with a limiting translation factor and inactivates (or sequestrates) the putative translation factor. The detailed mechanism of translational inhibition by the phosphorylated eIF3F remains unknown. A further investigation is in progress to understand the molecular mechanism of translational inhibition by CDK11/p58-dependent eIF3F phosphorylation.

Blocking eIF3F phosphorylation by knockdown of CDK11/p58 (Fig. 2c) or by overproduction of unphosphorylatable eIF3F (Fig. 7) in M phase cells, synchronized by nocodazole treatment, restored translation in $\mathrm{M}$ phase by approximately $35 \%$ and $50 \%$, respectively, compared with translation in interphase (Figs. 2, 7). The partial restoration, even after blocking the effect of CDK11/p58, is likely attributed to two reasons: (1) other mechanism(s), such as mitosis-specific binding of 14-3-3 $\sigma$ to eIF4F 4B [65] and/ or mitosis-specific activation of PKR, which results in phosphorylation of eIF2 $\alpha$ [23], may also contribute to the translational repression in $\mathrm{M}$ phase; (2) the contribution of translational repression by the toxic effect of nocodazole, which is unrelated to the M phase-specific translation inhibition [60]. The authors suggested that phosphorylation of eIF2 $\alpha$ induced by nocodazole treatment inhibits translation regardless of cell cycle [60].

Recently, Tanenbaum and his colleagues showed that M phase-specific translational inhibition occurs using a different cell cycle blocker, RO-3306 (CDK1 inhibitor), and genome-wide ribosome profiling analysis [15]. The authors showed that overall translation efficiency decreases approximately 35\% in M phase compared with G1 and G2 phases through ${ }^{35} \mathrm{~S}$-methionine labeling of newly synthesized proteins using a cell cycle arrest-and-resumption approach with RO-3306.

In this study, we also performed a cell cycle arrest-andresumption experiment using double thymidine block and puromycine labeling (Fig. 8). We used this approach to minimize the synchronizing chemical effect in $M$ phase and the stress generation in protein labeling process; that is, the recovery time after the cell cycle arrest is longer in the thymidine block than RO-3306 treatment ( 9 h vs. $45 \mathrm{~min}$ ), and the methionine starvation step is not required for the SUnSET method. Through this approach, we found that overall translation decreases to about $50 \%$ in M phase cells (Fig. 8b). To our surprise, the translational repression in $\mathrm{M}$ phase was not observed at all in the cells ectopically expressing eIF3F(A3A4). The results indicate that strong repression of overall translation occurs in $\mathrm{M}$ phase cells under normal conditions and that the phosphorylation of eIF3F by CDK11/ p58 plays a major role in the translational repression in $\mathrm{M}$ phase. Moreover, the results suggest that the partial restoration of translation in M phase cells, expressing eIF3F(A3A4) and synchronized by nocodazole (Fig. 7b), is attributed to a toxic effect of nocodazole.

Even though mitotic translational repression is a wellknown feature of mammalian cells, the physiological roles of translational modulation during cell cycle progression are not clearly understood. We speculate possible roles of translational repression during $M$ phase. (1) Translation repression of some genes during mitosis is needed for cell cycle progression from $\mathrm{M}$ to next $\mathrm{G} 1$ phase. For example, the specific translational inhibition of Emi1 gene, an inhibitor of anaphase-promoting complex (APC) formation, is required for the activation of APC during M phase, which in turn is needed for cell cycle progression [15]. (2) Translational repression during $\mathrm{M}$ phase would minimize the synthesis of aberrant polypeptides encoded in immature pre-mRNAs that are potentially exposed to translational machineries in the 
cytosol during $\mathrm{M}$ phase by the disappearance of the nuclear envelope [66]. (3) The reduction of cap-dependent translation during $\mathrm{M}$ phase seems to contribute to IRES-dependent translation by relieving the competition of limited translation factors [67].

An interesting relationship between cap-dependent and IRES-dependent translation during $M$ phase was revealed via investigations into the role of a tumor suppressor gene, 14-3-3 $\sigma$, in $\mathrm{M}$ phase-specific translational regulation [65]. The authors showed that $14-3-3 \sigma$ is required for $M$ phasespecific translation repression that is in turn required for IRES-dependent translation of CDK11/p58. Knockdown of 14-3-3 $\sigma$ resulted in increased cap-dependent translation and decreased IRES-dependent translation of CDK11/p58 during $\mathrm{M}$ phase, which in turn lead to impaired cytokinesis and the accumulation of binucleate cells [65]. Addition of rapamycin, which inhibits cap-dependent translation but not cap-independent translation, to the 14-3-3 $\sigma$ knockdown cells restored the mitotic translation of CDK11/p58 and nullified the aberrant mitotic phenotype. Moreover, the mitosis-

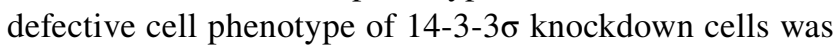
partially rescued by ectopic expression of CDK11/p58 [65]. Considering these data and our results presented here, which shows that CDK11/p58 actively reduces cap-dependent translation by phosphorylating eIF3F, the effect of CDK11/ p58 expression in 14-3-3 $\sigma$ knockdown cells is, at least in part, attributed to cap-dependent translational repression by CDK11/p58.

Translational regulation by CDK11 and eIF3F pair seems to have deep roots in evolutionary history. Neither CDK11 nor eIF3F homologue exists in $S$. cerevisiae, but both CDK11 and eIF3F homologues exist from Schizosaccharomyces pombe (S. pombe) to humans. Furthermore, the region corresponding to CDK11/p46 exists in all CDK11 homologues from $S$. pombe to humans, and one of the CDK11/ p46 phosphorylation sites in eIF3F (Thr119) exists in all eIF3F homologues (Fig. S7a). In contrast, neither CDK11/ p58 nor its target phosphorylation site in eIF3F exists in $S$. pombe (Fig. S7a). This indicates that M phase-specific translational repression by an isoform of CDK11 may not occur in $S$. pombe. Both cyclin D family members and the region in CDK11 corresponding to CDK11/p58 are conserved from Caenorhabditis elegans (C. elegans) to humans, and one of the CDK11/p58 target sites in eIF3F (Ser258) is also conserved from C. elegans to humans (Fig. S7a). This may indicate that cell cycle-dependent translational regulation by a CDK11 isoform (CDK11/p58) functions from C. elegans to humans. Other cell cycle-dependent translational regulation mechanisms that have been suggested to function during $\mathrm{M}$ phase are not as well conserved evolutionarily as the CDK11 and eIF3F pair. For example, the CDK1 phosphorylation site in eIF4G1, which was suggested to function in M phasespecific translational repression [22], is conserved only in mammals (Fig. S7b). In addition, PKR, which was also suggested to function during $\mathrm{M}$ phase-specific translational repression [23], exists only in vertebrates. The evolutionary aspect of $\mathrm{M}$ phase-specific translational repression by eIF3F and CDK11/p58 should be investigated experimentally in the future.

Acknowledgements This research was supported by Basic Science Research Program through the National Research Foundation of Korea (NRF) funded by the Ministry of Science, ICT and Future Planning (No. NRF-2017R1A2B3009902), and by the NRF Grant funded by the Korean Government (MSIT) (No. NRF-2019M3E5D6063871).

Author contributions SA designed the project, performed experiments, interpreted and analyzed data, and wrote the manuscript. OSK and JY performed the experiments. SKJ designed experiments, and wrote and edited the manuscript.

\section{Compliance with ethical standards}

Conflict of interest The authors declare no competing interests.

Open Access This article is licensed under a Creative Commons Attribution 4.0 International License, which permits use, sharing, adaptation, distribution and reproduction in any medium or format, as long as you give appropriate credit to the original author(s) and the source, provide a link to the Creative Commons licence, and indicate if changes were made. The images or other third party material in this article are included in the article's Creative Commons licence, unless indicated otherwise in a credit line to the material. If material is not included in the article's Creative Commons licence and your intended use is not permitted by statutory regulation or exceeds the permitted use, you will need to obtain permission directly from the copyright holder. To view a copy of this licence, visit http://creativecommons.org/licenses/by/4.0/.

\section{References}

1. Jackson RJ, Hellen CU, Pestova TV (2010) The mechanism of eukaryotic translation initiation and principles of its regulation. Nat Rev Mol Cell Biol 11(2):113-127. https://doi.org/10.1038/ nrm2838

2. Sonenberg N, Hinnebusch AG (2009) Regulation of translation initiation in eukaryotes: mechanisms and biological targets. Cell 136(4):731-745. https://doi.org/10.1016/j.cell.2009.01.042

3. Buttgereit F, Brand MD (1995) A hierarchy of ATP-consuming processes in mammalian cells. Biochem J 312(Pt 1):163-167

4. Russell JB, Cook GM (1995) Energetics of bacterial growth: balance of anabolic and catabolic reactions. Microbiol Rev 59(1):48-62

5. Ron D, Harding HP (2007) eIF2 $\alpha$ Phosphorylation in cellular stress responses and disease. In: Sonenberg N, Hershey JW, Mathews MB (eds) Translational control in biology and medicine. Cold Spring Harbor Laboratory Press, Cold Spring Harbor, pp 349-372. https://doi.org/10.1101/087969767.48.345

6. Krishnamoorthy T, Pavitt GD, Zhang F, Dever TE, Hinnebusch AG (2001) Tight binding of the phosphorylated alpha subunit of initiation factor 2 (eIF2alpha) to the regulatory subunits of guanine nucleotide exchange factor eIF2B is required for inhibition of translation initiation. Mol Cell Biol 21(15):5018-5030. https ://doi.org/10.1128/MCB.21.15.5018-5030.2001 
7. Sudhakar A, Ramachandran A, Ghosh S, Hasnain SE, Kaufman RJ, Ramaiah KV (2000) Phosphorylation of serine 51 in initiation factor 2 alpha (eIF2 alpha) promotes complex formation between eIF2 alpha(P) and eIF2B and causes inhibition in the guanine nucleotide exchange activity of eIF2B. Biochemistry 39(42):12929-12938

8. Gingras AC, Gygi SP, Raught B, Polakiewicz RD, Abraham RT, Hoekstra MF, Aebersold R, Sonenberg N (1999) Regulation of 4E-BP1 phosphorylation: a novel two-step mechanism. Genes Dev 13(11):1422-1437. https://doi.org/10.1101/gad.13.11.1422

9. Brunn GJ, Hudson CC, Sekulic A, Williams JM, Hosoi H, Houghton PJ, Lawrence JC Jr, Abraham RT (1997) Phosphorylation of the translational repressor PHAS-I by the mammalian target of rapamycin. Science 277(5322):99-101. https://doi. org/10.1126/science.277.5322.99

10. Norbury C, Nurse P (1992) Animal cell cycles and their control. Annu Rev Biochem 61:441-470. https://doi.org/10.1146/annur ev.bi.61.070192.002301

11. Nigg EA (2001) Mitotic kinases as regulators of cell division and its checkpoints. Nat Rev Mol Cell Biol 2(1):21-32. https://doi. org/10.1038/35048096

12. Sullivan M, Morgan DO (2007) Finishing mitosis, one step at a time. Nat Rev Mol Cell Biol 8(11):894-903. https://doi. org/10.1038/nrm 2276

13. Fan H, Penman S (1970) Regulation of protein synthesis in mammalian cells. II. Inhibition of protein synthesis at the level of initiation during mitosis. J Mol Biol 50(3):655-670

14. Konrad CG (1963) Protein synthesis and RNA synthesis during mitosis in animal cells. J Cell Biol 19:267-277

15. Tanenbaum ME, Stern-Ginossar N, Weissman JS, Vale RD (2015) Regulation of mRNA translation during mitosis. Elife. https://doi. org/10.7554/eLife.07957

16. Marash L, Liberman N, Henis-Korenblit S, Sivan G, Reem E, Elroy-Stein O, Kimchi A (2008) DAP5 promotes cap-independent translation of Bcl-2 and CDK1 to facilitate cell survival during mitosis. Mol Cell 30(4):447-459. https://doi.org/10.1016/j.molce 1.2008.03.018

17. Pyronnet S, Dostie J, Sonenberg N (2001) Suppression of capdependent translation in mitosis. Genes Dev 15(16):2083-2093. https://doi.org/10.1101/gad.889201

18. Richter JD, Sonenberg N (2005) Regulation of cap-dependent translation by eIF4E inhibitory proteins. Nature 433(7025):477480. https://doi.org/10.1038/nature03205

19. Heesom KJ, Gampel A, Mellor H, Denton RM (2001) Cell cycledependent phosphorylation of the translational repressor eIF-4E binding protein-1 (4E-BP1). Curr Biol 11(17):1374-1379

20. Gwinn DM, Asara JM, Shaw RJ (2010) Raptor is phosphorylated by cdc2 during mitosis. PLoS ONE 5(2):e9197. https://doi. org/10.1371/journal.pone.0009197

21. Ramirez-Valle F, Badura ML, Braunstein S, Narasimhan M, Schneider RJ (2010) Mitotic raptor promotes mTORC1 activity, $\mathrm{G}(2) / \mathrm{M}$ cell cycle progression, and internal ribosome entry sitemediated mRNA translation. Mol Cell Biol 30(13):3151-3164. https://doi.org/10.1128/MCB.00322-09

22. Dobrikov MI, Shveygert M, Brown MC, Gromeier M (2014) Mitotic phosphorylation of eukaryotic initiation factor $4 \mathrm{G} 1$ (eIF4G1) at Ser1232 by Cdk1:cyclin B inhibits eIF4A helicase complex binding with RNA. Mol Cell Biol 34(3):439-451. https ://doi.org/10.1128/MCB.01046-13

23. Kim Y, Lee JH, Park JE, Cho J, Yi H, Kim VN (2014) PKR is activated by cellular dsRNAs during mitosis and acts as a mitotic regulator. Genes Dev 28(12):1310-1322. https://doi.org/10.1101/ gad.242644.114

24. Satyanarayana A, Kaldis P (2009) Mammalian cell-cycle regulation: several Cdks, numerous cyclins and diverse compensatory mechanisms. Oncogene 28(33):2925-2939. https://doi. org/10.1038/onc. 2009.170

25. Loyer P, Trembley JH, Lahti JM, Kidd VJ (1998) The RNP protein, RNPS1, associates with specific isoforms of the p34cdc2related PITSLRE protein kinase in vivo. J Cell Sci 111(Pt 11):1495-1506

26. Hu D, Mayeda A, Trembley JH, Lahti JM, Kidd VJ (2003) CDK11 complexes promote pre-mRNA splicing. J Biol Chem 278(10):8623-8629. https://doi.org/10.1074/jbc.M210057200

27. Cornelis S, Bruynooghe Y, Denecker G, Van Huffel S, Tinton S, Beyaert R (2000) Identification and characterization of a novel cell cycle-regulated internal ribosome entry site. Mol Cell 5(4):597-605

28. Li T, Inoue A, Lahti JM, Kidd VJ (2004) Failure to proliferate and mitotic arrest of CDK11(p110/p58)-null mutant mice at the blastocyst stage of embryonic cell development. Mol Cell Biol 24(8):3188-3197

29. Petretti C, Savoian M, Montembault E, Glover DM, Prigent C, Giet R (2006) The PITSLRE/CDK11p58 protein kinase promotes centrosome maturation and bipolar spindle formation. EMBO Rep 7(4):418-424. https://doi.org/10.1038/sj.embor.7400639

30. Zong H, Chi Y, Wang Y, Yang Y, Zhang L, Chen H, Jiang J, Li Z, Hong Y, Wang H, Yun X, Gu J (2007) Cyclin D3/CDK11p58 complex is involved in the repression of androgen receptor. Mol Cell Biol 27(20):7125-7142. https://doi.org/10.1128/MCB.01753 $-06$

31. Shi J, Feng Y, Goulet AC, Vaillancourt RR, Sachs NA, Hershey JW, Nelson MA (2003) The p34cdc2-related cyclin-dependent kinase 11 interacts with the p47 subunit of eukaryotic initiation factor 3 during apoptosis. J Biol Chem 278(7):5062-5071. https ://doi.org/10.1074/jbc.M206427200

32. Shi J, Hershey JW, Nelson MA (2009) Phosphorylation of the eukaryotic initiation factor $3 \mathrm{f}$ by cyclin-dependent kinase 11 during apoptosis. FEBS Lett 583(6):971-977. https://doi. org/10.1016/j.febslet.2009.02.028

33. Ariza ME, Broome-Powell M, Lahti JM, Kidd VJ, Nelson MA (1999) Fas-induced apoptosis in human malignant melanoma cell lines is associated with the activation of the p34(cdc2)-related PITSLRE protein kinases. J Biol Chem 274(40):28505-28513

34. Tang D, Gururajan R, Kidd VJ (1998) Phosphorylation of PITSLRE p110 isoforms accompanies their processing by caspases during Fas-mediated cell death. J Biol Chem 273(26):16601-16607

35. Beyaert R, Kidd VJ, Cornelis S, Van de Craen M, Denecker G, Lahti JM, Gururajan R, Vandenabeele P, Fiers W (1997) Cleavage of PITSLRE kinases by ICE/CASP-1 and CPP32/CASP-3 during apoptosis induced by tumor necrosis factor. J Biol Chem 272(18):11694-11697

36. Damoc E, Fraser CS, Zhou M, Videler H, Mayeur GL, Hershey JW, Doudna JA, Robinson CV, Leary JA (2007) Structural characterization of the human eukaryotic initiation factor 3 protein complex by mass spectrometry. Mol Cell Proteom 6(7):1135-1146. https://doi.org/10.1074/mcp.M600399-MCP200

37. LeFebvre AK, Korneeva NL, Trutschl M, Cvek U, Duzan RD, Bradley CA, Hershey JW, Rhoads RE (2006) Translation initiation factor eIF4G-1 binds to eIF3 through the eIF3e subunit. J Biol Chem 281(32):22917-22932. https://doi.org/10.1074/jbc.M6054 18200

38. Villa N, Do A, Hershey JW, Fraser CS (2013) Human eukaryotic initiation factor $4 \mathrm{G}$ (eIF4G) protein binds to eIF3c, -d, and -e to promote mRNA recruitment to the ribosome. J Biol Chem 288(46):32932-32940. https://doi.org/10.1074/jbc.M113.517011

39. Peterson DT, Merrick WC, Safer B (1979) Binding and release of radiolabeled eukaryotic initiation factors 2 and 3 during $80 \mathrm{~S}$ initiation complex formation. J Biol Chem 254(7):2509-2516 
40. Benne R, Hershey JW (1976) Purification and characterization of initiation factor IF-E3 from rabbit reticulocytes. Proc Natl Acad Sci USA 73(9):3005-3009

41. Sokabe M, Fraser CS, Hershey JW (2012) The human translation initiation multi-factor complex promotes methionyl-tRNAi binding to the 40S ribosomal subunit. Nucleic Acids Res 40(2):905913. https://doi.org/10.1093/nar/gkr772

42. Avdulov S, Li S, Michalek V, Burrichter D, Peterson M, Perlman DM, Manivel JC, Sonenberg N, Yee D, Bitterman PB, Polunovsky VA (2004) Activation of translation complex eIF4F is essential for the genesis and maintenance of the malignant phenotype in human mammary epithelial cells. Cancer Cell 5(6):553-563. https://doi. org/10.1016/j.ccr.2004.05.024

43. Lazaris-Karatzas A, Montine KS, Sonenberg N (1990) Malignant transformation by a eukaryotic initiation factor subunit that binds to mRNA 5' cap. Nature 345(6275):544-547. https://doi. org/10.1038/345544a0

44. Li X, Zhu Q, Shi X, Cheng Y, Li X, Xu H, Duan X, Hsieh-Wilson LC, Chu J, Pelletier J, Ni M, Zheng Z, Li S, Yi W (2019) O-GlcNAcylation of core components of the translation initiation machinery regulates protein synthesis. Proc Natl Acad Sci USA 116(16):7857-7866. https://doi.org/10.1073/pnas.1813026116

45. Hershey JW (2015) The role of eIF3 and its individual subunits in cancer. Biochim Biophys Acta 1849(7):792-800. https://doi. org/10.1016/j.bbagrm.2014.10.005

46. Wen F, Zhou R, Shen A, Choi A, Uribe D, Shi J (2012) The tumor suppressive role of eIF3 $\mathrm{f}$ and its function in translation inhibition and rRNA degradation. PLoS ONE 7(3):e34194. https://doi. org/10.1371/journal.pone.0034194

47. Doldan A, Chandramouli A, Shanas R, Bhattacharyya A, Leong SP, Nelson MA, Shi J (2008) Loss of the eukaryotic initiation factor 3f in melanoma. Mol Carcinog 47(10):806-813. https:// doi.org/10.1002/mc.20436

48. Doldan A, Chandramouli A, Shanas R, Bhattacharyya A, Cunningham JT, Nelson MA, Shi J (2008) Loss of the eukaryotic initiation factor $3 \mathrm{f}$ in pancreatic cancer. Mol Carcinog 47(3):235-244. https://doi.org/10.1002/mc.20379

49. Shi J, Kahle A, Hershey JW, Honchak BM, Warneke JA, Leong SP, Nelson MA (2006) Decreased expression of eukaryotic initiation factor $3 \mathrm{f}$ deregulates translation and apoptosis in tumor cells. Oncogene 25(35):4923-4936. https://doi.org/10.1038/ sj.onc. 1209495

50. Wilson JE, Powell MJ, Hoover SE, Sarnow P (2000) Naturally occurring dicistronic cricket paralysis virus RNA is regulated by two internal ribosome entry sites. Mol Cell Biol 20(14):4990-4999

51. Chi Y, Zhang C, Zong H, Hong Y, Kong X, Liu H, Zou W, Wang Y, Yun X, Gu J (2011) Thr-370 is responsible for CDK11(p58) autophosphorylation, dimerization, and kinase activity. $\mathrm{J}$ Biol Chem 286(3):1748-1757. https://doi.org/10.1074/jbc. M110.107367

52. Ryu I, Park JH, An S, Kwon OS, Jang SK (2013) eIF4GI facilitates the MicroRNA-mediated gene silencing. PLoS ONE 8(2):e55725. https://doi.org/10.1371/journal.pone.0055725

53. Whitfield ML, Sherlock G, Saldanha AJ, Murray JI, Ball CA, Alexander KE, Matese JC, Perou CM, Hurt MM, Brown PO, Botstein D (2002) Identification of genes periodically expressed in the human cell cycle and their expression in tumors. Mol Biol Cell 13(6):1977-2000. https://doi.org/10.1091/mbc.02-02-0030

54. Kinoshita E, Kinoshita-Kikuta E, Koike T (2009) Separation and detection of large phosphoproteins using Phos-tag SDS-PAGE.
Nat Protoc 4(10):1513-1521. https://doi.org/10.1038/nprot .2009 .154

55. Schneider CA, Rasband WS, Eliceiri KW (2012) NIH Image to ImageJ: 25 years of image analysis. Nat Methods 9(7):671-675

56. Schmidt EK, Clavarino G, Ceppi M, Pierre P (2009) SUnSET, a nonradioactive method to monitor protein synthesis. Nat Methods 6(4):275-277. https://doi.org/10.1038/nmeth.1314

57. Koivomagi M, Valk E, Venta R, Iofik A, Lepiku M, Morgan DO, Loog M (2011) Dynamics of Cdk1 substrate specificity during the cell cycle. Mol Cell 42(5):610-623. https://doi.org/10.1016/j. molcel.2011.05.016

58. Dephoure N, Zhou C, Villen J, Beausoleil SA, Bakalarski CE, Elledge SJ, Gygi SP (2008) A quantitative atlas of mitotic phosphorylation. Proc Natl Acad Sci USA 105(31):10762-10767. https ://doi.org/10.1073/pnas.0805139105

59. des Georges A, Dhote V, Kuhn L, Hellen CU, Pestova TV, Frank J, Hashem Y (2015) Structure of mammalian eIF3 in the context of the 43S preinitiation complex. Nature. https://doi.org/10.1038/ nature 14891

60. Coldwell MJ, Cowan JL, Vlasak M, Mead A, Willett M, Perry LS, Morley SJ (2013) Phosphorylation of eIF4GII and 4E-BP1 in response to nocodazole treatment: a reappraisal of translation initiation during mitosis. Cell Cycle 12(23):3615-3628. https:// doi.org/10.4161/cc.26588

61. Zhang S, Cai M, Zhang S, Xu S, Chen S, Chen X, Chen C, Gu $\mathrm{J}$ (2002) Interaction of p58(PITSLRE), a G2/M-specific protein kinase, with cyclin D3. J Biol Chem 277(38):35314-35322. https ://doi.org/10.1074/jbc.M202179200

62. Smith MD, Arake-Tacca L, Nitido A, Montabana E, Park A, Cate JH (2016) Assembly of eIF3 mediated by mutually dependent subunit insertion. Structure 24(6):886-896. https://doi.org/10.1016/j. str.2016.02.024

63. Mazumder B, Sampath P, Seshadri V, Maitra RK, DiCorleto PE, Fox PL (2003) Regulated release of L13a from the 60S ribosomal subunit as a mechanism of transcript-specific translational control. Cell 115(2):187-198. https://doi.org/10.1016/s0092 -8674(03)00773-6

64. Arif A, Yao P, Terenzi F, Jia J, Ray PS, Fox PL (2018) The GAIT translational control system. Wiley Interdiscip Rev RNA. https:// doi.org/10.1002/wrna.1441

65. Wilker EW, van Vugt MA, Artim SA, Huang PH, Petersen CP, Reinhardt HC, Feng Y, Sharp PA, Sonenberg N, White FM, Yaffe MB (2007) 14-3-3sigma controls mitotic translation to facilitate cytokinesis. Nature 446(7133):329-332. https://doi.org/10.1038/ nature 05584

66. Pinol-Roma S, Dreyfuss G (1991) Transcription-dependent and transcription-independent nuclear transport of hnRNP proteins. Science 253(5017):312-314

67. Svitkin YV, Herdy B, Costa-Mattioli M, Gingras AC, Raught B, Sonenberg N (2005) Eukaryotic translation initiation factor $4 \mathrm{E}$ availability controls the switch between cap-dependent and internal ribosomal entry site-mediated translation. Mol Cell Biol 25(23):10556-10565. https://doi.org/10.1128/MCB.25.23.10556 $-10565.2005$

Publisher's Note Springer Nature remains neutral with regard to jurisdictional claims in published maps and institutional affiliations. 